\title{
Ética, valores pessoais e a compra de falsificados
}

\section{Matheus Lemos de Andrade, Ramon Silva Leite e Simone Teresinha Chaves de Andrada Ibrahim}

\section{RESUMO}

Tido como um comportamento desviante devido aos seus efeitos econômicos e sociais, a compra de falsificados é um comportamento enraizado e socialmente aceito entre diversos segmentos da sociedade brasileira. O presente estudo se fundamentou nas teorias sobre valores pessoais e ética para compreender e explicar a propensão à compra de produtos falsificados. Para tal, foi realizada uma pesquisa com 479 consumidores mineiros. A análise dos dados envolveu estatísticas descritivas, testes de comparação de média e Modelagem de Equações Estruturais (PLS). Os resultados revelam maior propensão à compra de falsificados entre consumidores com menor escolaridade, renda familiar e faixa etária. Verificou-se a influência positiva da racionalidade teleológica nas atitudes em relação aos falsificados, assim como uma relação negativa entre tais atitudes e a racionalidade deontológica. Sobre os valores pessoais, tem-se que enquanto os tipos motivacionais Estimulação e Hedonismo favorecem tais atitudes, a Autodeterminação e a Realização as inibem.

Palavras-Chave: Ética; Valores Pessoais; Compra de Falsificados; Ética no Consumo

\section{Ethics, Personal Values And The Purchase Of Counterfeits}

\section{ABSTRACT}

Understood as a deviant behavior due its economic and social effects, the purchase of counterfeits is a socially accepted behavior among several segments of Brazilian society. The present study was based on theories of personal values and ethics to understand and explain the propensity to buy counterfeit goods. For that, a survey was carried out with 479 consumers from Minas Gerais. Data analysis involved descriptive statistics, mean comparison tests, and Structural Equation Modeling (PLS). The results show a higher propensity to buy counterfeits among consumers with lower schooling, family income and age. A positive influence of the teleological rationality on the attitudes towards the counterfeit, as well a negative relation between such attitudes and the deontological rationality was verified. About personal values, the results show that while the motivational types Stimulation and Hedonism favor such attitudes, self-determination and the realization inhibit.

Keywords: Ethics; Personal values; Buy Counterfeits; Ethics in Consumption

Recebido em: 21/08/2018 Revisado em: 17/09/2018 Aprovado em: 28/11/2018

Check for updates

Matheus Lemos de Andrade (iD,

Programa de Pós-Graduação em Administração, Pontifícia Universidade Católica de Minas Gerais, Brasil; Faculdade de Administração Milton Campos, Brasil Doutor em Administração

matheus@institutoolhar.com.br

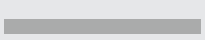

Ramon Silva Leite (iD) Programa de Pós-Graduação em Administração, Pontifícia Universidade Católica de Minas Gerais, Brasil Doutor em Administração

ramons|@pucminas.br

Simone Teresinha Chaves de Andrada Ibrahim (iD,

Faculdades Milton Campos, Brasil Mestre em Direito Empresarial

simonibra@bol.com.br 
Introdução

A produção de bens inspirada em ideias e estilos de terceiros é um fenômeno ancestral que pode ser notado na história da arte, da arquitetura e da moda. Segundo Chaudhry e Zimmerman (2009), os primeiros registros de falsificação encontrados na literatura se referem aos séculos XV e XVI, quando a ascensão da burguesia na Europa, acompanhada pela possibilidade de mobilidade social, motivou esta classe a copiar os signos ostentados pelas classes superiores. Conforme os autores, apesar dos registros da produção e consumo de falsificados serem anteriores a esta época, o aumento da utilização de marcas para identificar a origem e atestar autenticidade aos produtos estimulou a prática da contrafação.

Apesar da dificuldade de identificar de modo concreto qual a abrangência e a dimensão do mercado de falsificados (OECD/EUIPO, 2016; Chaudhry \& Zimmerman, 2009), basta uma visita aos centros comerciais de qualquer grande cidade brasileira para atestar a cultura disseminada de compra e consumo de tais produtos. O trabalho de Andrade, Leite e Salvador (2018) revela, a partir de um olhar interpretativo, como a compra e o ato de presentear com produtos falsificados tendem a serem percebidos como atos antiéticos somente quando o consumidor busca ludibriar os demais. Os relatos dos autores revelam que a percepção e o julgamento ético em relação à compra de falsificações ultrapassam a questão legal e derivam de um complexo conjunto de elementos relativos ao contexto, aos objetivos do consumidor e ao processo subjetivo de significação.

O estudo do SPC Brasil ${ }^{1}$ realizado em 2015 com a população (classes A, B e C) das 27 capitais brasileiras indica que 69\% dos entrevistados informaram já ter comprado algum falsificado. A última publicação do Conselho Nacional de Combate à Pirataria e Delitos Contra a Propriedade Intelectual (CNPC) intitulada Brasil Original (2011) estimava que o mercado de falsificados movimenta 600 bilhões de dólares ao ano em todo o mundo. Segundo o estudo, a falsificação de roupas, discos, brinquedos e cigarros gira em torno de 6 bilhões de reais ao ano, só no Brasil. $O$ mais recente estudo internacional sobre o consumo de falsificados realizado pelo Escritório de Propriedade Intelectual da União Europeia (EUIPO) estima que o mercado de falsificados em todo o mundo tenha movimentado 461 bilhões de dólares no ano de 2013, o que representa $2,5 \%$ do comércio mundial registrado naquele ano (OECD/EUIPO, 2016).

Enquanto objeto de investigação, o consumo de falsificados se constitui como um fenômeno complexo, que se mostra um terreno fértil e desafiador aos pesquisadores contemporâneos. A compreensão dos elementos que influenciam e motivam a compra e o consumo de falsificados é objeto de estudo de diversas investigações no campo do marketing. Os trabalhos de Eisend e Schuchert-Güler (2006), Lee e Yoo (2009) e Staake, Thiesse e Fleisch (2009) analisaram as publicações sobre o tema. Esses trabalhos revelam que a diversidade de pesquisas sobre a compra e o consumo de falsificados se faz

1 Consumo de Produtos de Luxo Falsificados: Maio de 2015. SPC Brasil / Meu Bolso Feliz. Disponível em: https://www.spcbrasil.org.br/uploads/st_imprensa/estudo_spc_brasil_falsificados1.pdf Acesso em: 10/04/2017. 
notar por diferentes abordagens epistemológicas, metodológicas e teóricas. Além disto, verifica-se que no campo do comportamento do consumidor há estudos que abordaram o consumo de falsificados estabelecendo enlaces com uma série de elementos, tais como atitudes, valores, cultura, marca, características demográficas, heurística, percepção de risco, ética, satisfação, origem do produto, influências sociais, materialismo, legalismo, preço, autoimagem do consumidor, prestígio do revendedor, paridade e percepção de qualidade, aspectos ideológicos, punição e penalidades associadas à compra de falsificados, facilidade de acesso, dentre outros. Apesar desta variedade, nota-se que o conhecimento sobre os aspectos que influenciam o consumo de falsificados permanece fragmentado e disperso (Eisend \& Schuchert-Güler, 2006; Swami, Chamorro-Premuzic, \& Furnham, 2009; Lee \& Yoo, 2009).

Em busca de elementos que possam explicar a compra de produtos falsificados, o presente estudo está fundamentado nas teorias dos Valores Pessoais (Schwartz et al., 2012) e das Decisões Éticas (Hunt \& Vitell, 1986; 1993; 2006). A escolha de tal fundamentação se justifica pela busca de um framework teórico que operacionaliza elementos suficientemente amplos e abstratos para promover uma investigação sobre o consumo de falsificados, sem a necessidade de se concentrar em categorias específicas de produtos. Desta forma, partiu-se da seguinte pergunta norteadora como problema de pesquisa: Qual a relação das características demográficas, das racionalidades éticas e dos valores pessoais com as atitudes e a propensão à compra de produtos falsificados? Dado o problema da pesquisa, os seguintes objetivos específicos motivaram o presente estudo: a) Verificar a existência de relações entre as características demográficas dos consumidores e as atitudes e a propensão à compra de falsificados; b) Verificar a existência de relações entre os valores pessoais e as racionalidades éticas dos consumidores e as atitudes de compra de falsificados.

Este artigo está estruturado em quatro seções além desta Introdução. Na Fundamentação Teórica são resgatados os elementos centrais relacionados à teoria dos valores pessoais e sobre ética no consumo. Ainda nesta parte foram resgatados e discutidos os estudos sobre o consumo de produtos falsificados. A seção seguinte descreve os procedimentos metodológicos empregados no estudo de campo e é seguida pela apresentação dos seus resultados. Por fim, a última parte se concentra na discussão dos achados desta pesquisa, bem como no apontamento de suas limitações e de sugestões para novos estudos.

\section{Fundamentação Teórica}

\section{Ética}

Sob a perspectiva da dignidade e da justiça social, a ética pode ser entendida como a vertente da filosofia que se interessa pela análise da conduta humana (Vazquez, 2007; Passos, 2006). Para Clavo (2008, p.120), a ética "é um conjunto de normas, princípios e razões que um sujeito compreendeu e estabeleceu como diretriz de sua conduta". No cerne da reflexão ética o indivíduo vivencia a conflituosa relação entre o egocentrismo e o altruísmo. 
Para Vazquez (2007), a discussão sobre comportamentos éticos se limita à análise de indivíduos conscientes e livres. Conscientes porque exigese a compreensão das consequências de seus atos e dos demais atores sociais para que possa fazer seu próprio julgamento. Livre, porque sendo resultado de uma obrigação, não será fruto da decisão do indivíduo, que agindo desta forma, não poderá ser condenado por seus comportamentos. Além da liberdade de ação, o autor considera a liberdade do homem para fazer seus próprios julgamentos.

No que se refere ao marketing e às atividades de consumo, a Teoria Geral da Ética no Marketing (Hunt \& Vitell, 1986; 1993; 2006) se apresenta como uma importante referência sobre o tema (Vida, Koklic, Kukar-Kinney, \& Penz 2012; Tang, Tian, \& Zaichkowsky, 2014). Tal teoria descreve um modelo processual sobre decisões que envolvem algum tipo de dilema ético.

O Modelo Hunt e Vitell (2006) é iniciado com a percepção da existência de um dilema ético por parte do indivíduo. Amparado na concepção da Racionalidade Limitada (Simon, 1972), o passo seguinte pressupõe que o indivíduo identifique as possíveis soluções para tal dilema, considerando as informações que possui ou as quais terá acesso. O julgamento ético, considerado o "coração" desse modelo, é o passo seguinte que deriva de dois tipos de racionalidades: a) A deontologia é orientada por princípios pré-estabelecidos, tais como leis, normas e valores pessoais. Conforme a deontologia, a definição do que é certo ou errado independe das consequências de um ato e se concentra exclusivamente no respeito ou não a tais regras; b) A teleologia concentra sua avaliação nas consequências de um ato ou comportamento. Diferente da deontologia, o pensamento teleológico desconsidera qualquer tipo de regra, norma ou valor previamente estabelecido para avaliar se um ato ou comportamento é ético ou não.

Considerada como uma das principais contribuições de Hunt e Vitell (2006), o modelo prevê que o julgamento ético é derivado de uma análise conjunta que congrega as racionalidades deontológicas e teleológicas. Apesar de reconhecer que os julgamentos éticos podem se concentrar em uma única perspectiva, os autores afirmam ser incomum ignorar completamente uma ou outra orientação (Hunt \& Vitell, 2006). Sobre tal ponto, verifica-se a concordância de outros autores no que se refere à insuficiência de cada corrente para resolver os dilemas éticos vivenciados pelos homens reais (Morin, 2007; Cotrin, 2002; Vazquez, 2007; Baker, 2008; Patrus-Pena \& Castro, 2010). O pensamento deontológico falha por estabelecer regras absolutas que possam ser consideradas universais e por não apresentar alternativas quando dois deveres éticos se impõem. Já o pensamento teleológico exige alguma referência para determinar quais consequências são desejáveis. Sendo assim, inevitavelmente a Teleologia recorre a algum tipo de referência prévia, o que traz à tona o pensamento deontológico, ainda que de modo secundário.

Dado que o foco do presente estudo é a identificação dos elementos que influenciam a propensão à compra de falsificados para avaliação da influência da ética em relação a tal comportamento, optou-se por trabalhar com a análise da influência das racionalidades deontológicas e teleológicas isoladamente, a partir da escala proposta por Burns e Kiecker (1995). Apesar 
de reconhecer que os indivíduos podem considerar ambas as racionalidades em seus julgamentos, o tratamento em separado de tais racionalidades atende ao objetivo de identificar a influência de cada uma em relação ao fenômeno de compra de falsificados.

\section{Valores Pessoais}

Dentre os elementos individuais que influenciam os consumidores, os valores pessoais se destacam não só por sua robusta fundamentação teórica, mas também pela praticidade de aplicação em estudos empíricos. Os valores pessoais podem ser usados como critérios padronizados, têm forte potencial para explicar comportamentos, apresentam parcimônia e são estáveis ao longo do tempo (Kamakura \& Mazzon, 1991; Andrade \& Leite, 2017).

As crenças, atitudes e valores são organizados em conjunto e integrados em um sistema cognitivo. Os valores não atuam de modo isolado, mas se articulam entre si, caracterizando o sistema de valores do indivíduo (Rokeach, 1973; Kamakura \& Mazzon, 1991; Schwartz et al. 2012). Os valores são passados por meio das interações sociais e da cultura. Contudo, é a partir das vivências e experiências que o indivíduo desenvolve o seu próprio sistema de valores (Kluckhohn, 1951; Rokeach, 1973; Rohan, 2000; Tamayo, 2007).

O sistema de valores pessoais pode explicar avaliações, decisões e o esforço dos consumidores em relação a pessoas, objetos e ideias. Os valores possuem grande utilidade em análises comportamentais, uma vez que influenciam nossos desejos, a forma como nos comportamos para alcançá-los e os julgamentos em relação às ofertas disponíveis. "Valores também são responsáveis pela seleção e manutenção dos objetivos e metas pelos quais os seres humanos se esforçam, ao mesmo tempo que regulam os métodos e maneiras pelos quais estes esforços ocorrem" (Vinson Scott, \& Lamont, 1977, p. 45).

A abordagem estrutural dos valores individuais e sociais de Schwartz et al. (2012) se mostra como a principal referência contemporânea sobre o tema (Calvosa, 2012; Bilsky, 2009). Schwartz (1992) assume cinco características básicas que definem o que são valores. "Valores (1) são concepções ou crenças, (2) pertencem a estados finais ou comportamentos desejáveis, (3) transcendem situações específicas, (4) guiam a seleção ou avaliação de comportamentos e eventos, e (5) são ordenados pela importância relativa" (Schwartz, 1992, p.4).

Schwartz (1992) coletou amostras em vinte países e concluiu que apesar dos inúmeros valores humanos encontrados em diferentes culturas, é possível agrupá-los dez categorias, a partir dos elementos motivacionais que os sustentam. Além disto, de modo inovador, o autor demonstra a existência de relações dinâmicas entre tais categorias, o que não permite tratá-las como elementos isolados uns dos outros. Sendo assim, cada tipo motivacional foi posicionado conforme sua relação com os demais, o que originou o continuum dos tipos motivacionais e as categorias de "segunda ordem”. São elas: Autotranscedência, Abertura à Mudança, Autopromoção e Conservação (Figura 1 - A). 
Passados vinte anos de sua publicação original (Schwartz, 1992), Schwartz et al. (2012) propuseram uma versão refinada de tal teoria. Nessa versão refinada, os autores defendem a existência de dezenove tipos motivacionais, além de adicionar duas grandes dimensões teóricas criadas a partir da relação entre os tipos motivacionais de segunda ordem: a) Foco Social versus Foco Pessoal; b) Crescimento e Auto-Expansão versus Autoproteção e Evitação de Ansiedade. (Figura 1 - B).

A

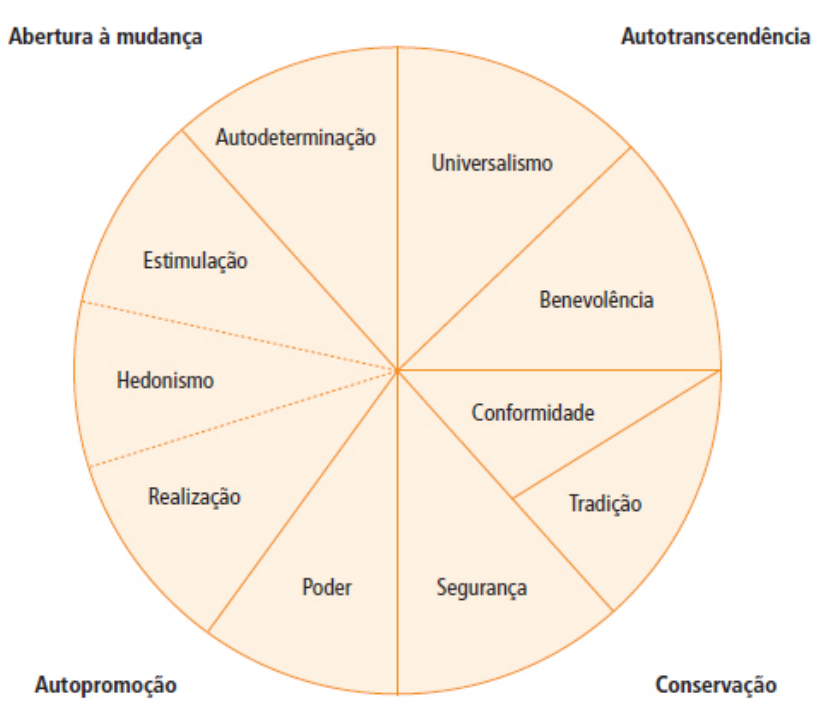

B

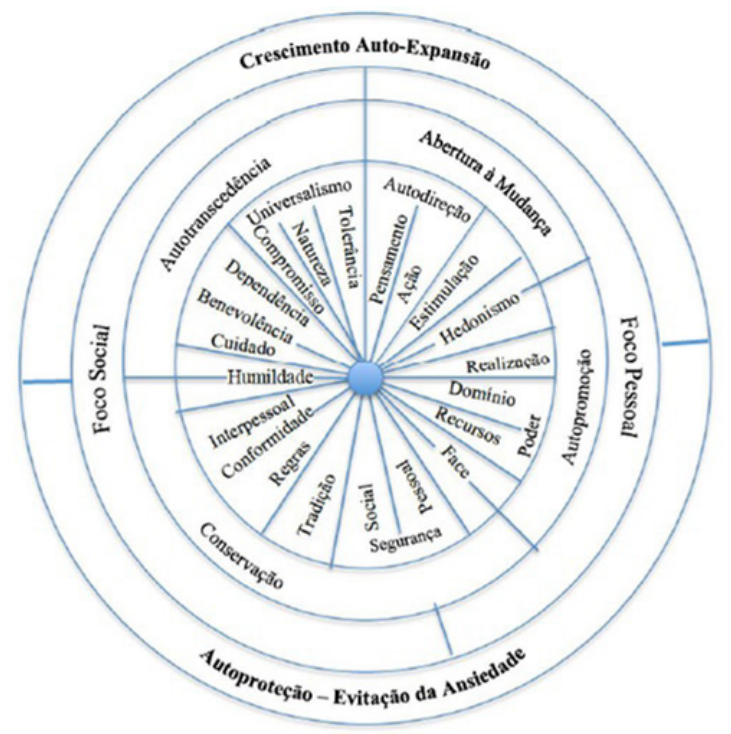

Figura 1. Continuum dos Tipos Motivacionais de Schwartz (1992) e Schwartz et al. (2012)

Fonte: Adaptado de Torres, Schwartz e Nascimento (2016, p. 343) e Araújo, Bilsky e Moreira (2012, p.77)

Em análise à Teoria Refinada dos Valores Pessoais (Schwartz et al. 2012), Torres et al. (2016) reforçam sua compatibilidade com a teoria original (Schwartz, 1992) ao identificar que os 19 tipos motivacionais da versão atualizada do continuum motivacional se distribuem de modo similar aos 10 tipos motivacionais que moldam a proposição original de tal continuum. "A teoria refinada compartilha com a teoria original o fato dos 19 valores mais estreitamente definidos abrangerem o mesmo continuo motivacional proposto pelos 10 valores originais" (Torres et al., 2016, p. 343).

Conforme Schwartz et al. (2012), os valores são construtos motivacionais que assumem um caráter consciente e possuem a função de responder às três exigências ou tarefas universais da existência humana: necessidades biológicas, de interação social, de sobrevivência e de bemestar da coletividade. A Tabela 01 apresenta as definições básicas dos tipos motivacionais identificados por Schwartz (1992), bem como identifica suas categorias de segunda ordem e fontes motivacionais.

No campo do Marketing, a teoria dos valores pessoais tem sido largamente utilizada, tendo ampla aceitação no meio acadêmico (Munson \& McQuarrie, 1988), inclusive no Brasil (Andrade \& Leite, 2017). Segundo os autores, os estudos sobre valores pessoais em Marketing podem ser 
utilizados para diferentes finalidades, tais como: identificação de grupos culturais e criação de estereótipos de consumidores, análises de subculturas e classes sociais, segmentação de mercado, compreensão das motivações de consumo, relacionamento com marcas, processos de decisão de compra e avaliação de atributos de produtos.

Tabela 01. Dimensões e Tipos Motivacionais de Schwartz (1992)

\begin{tabular}{|c|c|c|c|}
\hline Categoria & Tipo Motivacional & Conceito & $\begin{array}{l}\text { Fonte(s) } \\
\text { Motivacional(is) }\end{array}$ \\
\hline \multirow{2}{*}{ Autopromoção } & Poder & $\begin{array}{l}\text { Status social, prestígio, controle ou dominação sobre pessoas e } \\
\text { recursos }\end{array}$ & $\begin{array}{l}\text { Interação social } \\
\text { Bem-estar coletivo }\end{array}$ \\
\hline & Realização & $\begin{array}{l}\text { Sucesso pessoal por meio de demonstração de competência } \\
\text { conforme os padrões sociais }\end{array}$ & $\begin{array}{l}\text { Interação social } \\
\text { Bem-estar coletivo }\end{array}$ \\
\hline $\begin{array}{l}\text { Autopromoção e } \\
\text { Abertura à Mudança }\end{array}$ & Hedonismo & Prazer e senso de gratificação individual & Biológica \\
\hline \multirow[b]{2}{*}{ Abertura à Mudança } & Estimulação & Excitação, novidades e desafios ao longo da vida & Biológica \\
\hline & Autodeterminação & $\begin{array}{l}\text { Independência de pensamento e de ação ao longo das } \\
\text { escolhas, da criação e de exploração }\end{array}$ & $\begin{array}{l}\text { Biológica } \\
\text { Interação social }\end{array}$ \\
\hline \multirow[b]{2}{*}{ Autotranscedência } & Universalismo & $\begin{array}{l}\text { Compreensão, apreciação, tolerância e proteção do bem-estar } \\
\text { social e da natureza }\end{array}$ & $\begin{array}{l}\text { Biológicas } \\
\text { Interação social }\end{array}$ \\
\hline & Benevolência & $\begin{array}{l}\text { Preservação e aprimoramento do bem-estar das pessoas com } \\
\text { as quais se relaciona }\end{array}$ & $\begin{array}{l}\text { Biológicas } \\
\text { Interação social } \\
\text { Bem-estar coletivo }\end{array}$ \\
\hline \multirow{3}{*}{ Conservação } & Tradição & $\begin{array}{l}\text { Respeito, compromisso e aceitação dos costumes e ideias } \\
\text { tradicionais, culturais ou religiosas }\end{array}$ & Bem-estar coletivo \\
\hline & Conformidade & $\begin{array}{l}\text { Restrição de ações, inclinações e impulsos que violam } \\
\text { expectativas ou normas sociais. }\end{array}$ & $\begin{array}{l}\text { Interação social } \\
\text { Bem-estar coletivo }\end{array}$ \\
\hline & Segurança & $\begin{array}{l}\text { Segurança, harmonia e estabilidade da sociedade, dos } \\
\text { relacionamentos e do próprio indivíduo. }\end{array}$ & Bem-estar coletivo \\
\hline
\end{tabular}

Fonte: Adaptado de Schwartz (1994)

\section{Compra e Consumo de Falsificados}

A compreensão dos elementos que influenciam e motivam a compra e o consumo de falsificados é objeto de estudo de inúmeras investigações no campo do Marketing. A literatura reconhece dois tipos de consumidores de falsificados: os que são enganados, ou seja, compram o falsificado pensando ser original; e os conscientes, que sabem que estão comprando falsificações. Mesmo que seja difícil reconhecer a diferença entre os falsificados e os originais, grande parte dos consumidores adquire a consciência da compra de uma falsificação por meio de outros elementos, tais como o preço muito abaixo da média de mercado ou o local da compra (Grossman \& Shapiro, 1988; Nia \& Zaichkowsky, 2000; Gentry, Putrevu, Shutz, \& Clifford, 2001).

No âmbito do Marketing, os estudos de comportamentos não-enganosos buscam identificar os fatores que favorecem este comportamento e aqueles que o inibem. Verifica-se que os elementos que influenciam a compra e o consumo de falsificados se constituem como as características do produto ou do mercado no qual o falsificado se insere; elementos culturais 
e características individuais, que se dividem entre psicográficas, tais como valores e atitudes; e demográficas, tais como idade, nível educacional, renda, ocupação e estado civil (Eisend \& Schuchert-Güler, 2006). Em coerência com Eisend \& Schuchert-Güler (2006), Staake et al. (2009; 2012) afirmam que as principais questões avaliadas pelos estudos sobre consumo nãoenganoso de falsificados se relacionam com consciência, intenções de compra, características demográficas e atitudes.

Em relação às características do mercado ou do produto, os principais elementos que influenciam a compra de falsificados são: baixo custo, funcionalidade, características do varejo e o status atribuído à marca falsificada (Eisend \& Schuchert-Güler, 2006; Lee \& Yoo, 2009). Reconhecendo a possibilidade de acesso aos "produtos de status" por meio da compra de falsificados, diversos estudos defendem que a percepção de valor superior na compra de tais produtos advém do baixo custo (Grossman \& Shapiro, 1988; Gentry et al., 2001; Cordell, Wongtada, \& Kieschnick, 1996; Penz \& Stottinger, 2005; Strehlau, 2004). Por outro lado, outros estudos revelam que tais produtos também são comprados por suas funcionalidades (Van Kempen, 2003; Cordell et al., 1996; Penz \& Stottinger, 2005). Sendo assim, tem-se que boa parte dos consumidores adquire falsificações, considerando os benefícios funcionais e o status de tais produtos, aliados ao seu baixo custo de aquisição. Considerando os aspectos situacionais, Penz e Stottinger (2005) e Cordell et al. (1996) identificaram que a disposição dos consumidores para a compra de falsificados é relacionada com as condições dos varejistas e com a acessibilidade a tais produtos. Quanto mais fácil o acesso e quanto melhores são as condições dos varejistas, maior é a propensão à compra de falsificados.

Em estudo de abrangência nacional Reis Junior (2018) identificou que, no Brasil, a compra de produtos de luxo falsificados é justificada a partir de variáveis individuais, de contexto e relativas à categoria de produtos. Dentre as variáveis individuais, os autores relatam que a origem familiar, situação financeira e o conhecimento sobre falsificados influenciam a compra de tais produtos. Já entre as variáveis de contexto, o estudo confirma a influência social e a busca de status como elementos explicativos de tal comportamento. Por fim, dentre as variáveis de produto, o trabalho confirma a relevância dos canais de compra, dos atributos do produto de interesse do consumidor e dos tipos de fonte de informação utilizadas ao longo do processo de decisão.

Uma vez discutidas as teorias sobre ética e valores pessoais e apresentados relevantes aspectos relativos à compra de falsificados, os tópicos seguintes resgatam os resultados de estudos que analisaram este fenômeno à luz dos objetivos da pesquisa em tela.

\section{Características demográficas e a compra de falsificados}

Apesar de haver estudos que defendem que as características demográficas não influenciam a compra de falsificados (Bloch, Bush, \& Campbell, 1993), verificam-se outros que contradizem essa posição (Cheung \& Prendergast, 2006; Eisend, Hartman \& Apaolaza, 2017). Há também autores 
que concordam que os efeitos das características sócio demográficas no consumo de falsificados variam conforme a categoria do produto (Eisend \& Schuchert-Güler, 2006; Lee \& Yoo, 2009; Staake et al., 2009).

Por se tratarem de critérios utilizados para caracterização do público investigado, a maior parte dos estudos quantitativos sobre a compra de falsificados analisa sua relação com as variáveis sócio demográficas. Uma análise geral sobre tais resultados aponta para fortes discrepâncias, que podem ser explicadas pelas diferenças entre os métodos de mensuração utilizados entre as categorias de produtos e entre os públicos investigados (Lee \& Yoo, 2009).

Com o objetivo de avaliar a existência de relações entre as características sócio demográficas e as atitudes e propensão à compra de falsificados de um modo geral, e não em relação a uma categoria de produto específica, o presente estudo se propõe a analisar as seguintes variáveis: faixa etária; sexo; religião; religiosidade; renda familiar e nível de escolaridade. Considerando a insipiência do conhecimento sobre tal assunto, o estudo em tela assume um caráter exploratório e se propõe a verificar a existência de tais relações. Sendo assim, considerando o foco em novas descobertas, não foram propostas hipóteses para a relação entre as variáveis sócio demográficas e as atitudes e a propensão à compra de falsificados.

\section{Ética e compra de falsificados}

São raros os estudos empíricos que investigaram a relação entre a compra de falsificados e a ética do consumidor. Nill e Shultz (1996) afirmam que a compra de produtos falsificados é um típico dilema ético e que os consumidores utilizam os julgamentos deontológico e teleológico para avaliar tal comportamento. Considerando o pensamento deontológico, a compra de falsificados estaria relacionada aos problemas morais imbricados no seu consumo, tal como o desrespeito aos direitos autorais. Os autores sugerem que a compra de falsificados poderia ser associada a um ato desonesto, tal como "roubar". No que se refere ao pensamento teleológico, desconsiderando os efeitos mais amplos em relação ao consumo de falsificados, tem-se que os consumidores de falsificados tendem a verificar sua similaridade com os originais. Quanto mais similares forem em sua aparência, funcionalidade e durabilidade, maiores as chances de optar pelo falsificado, devido ao baixo custo.

Apesar do vasto relato sobre a aceitação social a respeito da compra e do consumo de falsificados (Vitell \& Muncy, 2005; Nill \& Shultz, 2009; Prendergast, Hing Chuen, \& Phau, 2002; Solomon \& O’Brien, 1990; Gupta, Gould, \& Pola, 2004; Casali, Paes, Machado, Medeiros \& Aragão, 2010; Lau, 2007; Andrade, Leite, \& Salvador, 2018), uma análise sobre os estudos empíricos revela a influência significativa da ética na compra de produtos falsificados. De um modo geral, sabe-se que quanto maior a sensibilidade ética do consumidor (Vitell \& Muncy, 1998; 2005), menor é a propensão à compra de falsificados (Penz \& Stöttinger, 2005; Santos, Gonçalves Filho, \& Falce, 2017). Segundo Rabello, Leite e Gonçalves Filho (2016), consumidores que apresentam forte concordância com justificativas deontológicas 
contrárias ao consumo de falsificados têm menor propensão à compra de tais produtos. Já aqueles que concordam com as justificativas teleológicas para o consumo de falsificados tendem a apresentar maior propensão à compra. Sendo assim, no que se refere à ética, o presente estudo assume as seguintes hipóteses:

H1: A racionalidade Deontológica se relaciona negativamente com as atitudes em relação aos produtos falsificados;

H2: A racionalidade Teleológica se relaciona positivamente com as atitudes em relação aos produtos falsificados;

\section{Valores pessoais e a compra de falsificados}

Verifica-se o baixo número de estudos que tenham avaliado a relação dos valores pessoais com a compra de produtos falsificados. Em discussão sobre a relação dos valores culturais e o consumo de falsificados de luxo, Reis Junior e Torres (2018) defendem que esse comportamento tende a ser motivado pela busca de diferenciação social em nível individual ou coletivo. Sendo assim, concluem que a dimensão vertical dos valores culturais (Triandis \& Gelfand, 1998) tende a justificar o fenômeno de compra e consumo de falsificações, além de enfatizarem as motivações hedônicas como uma possivel explicação para tais comportamentos.

Dentre os estudos que investigaram tal relação a partir de algum inventário de valores humanos, tem-se que Furnham e Valgeirsson (2007) identificaram uma relação negativa entre o valor Tradição e o consumo de falsificados. No Brasil, o estudo de Pires (2008) identificou que os consumidores com maior propensão à compra de pirataria são os que apresentam maior preocupação com os valores individualistas.

No que se refere à relação entre os valores pessoais e as atitudes e a propensão à compra de falsificados o estudo em tela se apresenta como um esforço exploratório de investigação. Sendo assim, estabeleceu-se a seguinte hipótese sobre a relação entre os valores pessoais e as atitudes em relação aos falsificados:

H3: Os valores pessoais influenciam as atitudes em relação aos produtos falsificados.

Considerando que os valores pessoais e as racionalidades éticas são construtos amplos, que não tratam diretamente do comportamento de compra de falsificados, tem-se que o estabelecimento de relações entre essas variáveis e a propensão à compra de falsificados se mostra inadequada, principalmente quando se considera o princípio da compatibilidade (Ajzen, 2005), que trata do nível de generalidade-especificidade das variáveis explicativas que são utilizadas para explicação de comportamentos específicos. De acordo com o autor, variáveis mais amplas, como é o caso dos valores pessoais e das racionalidades éticas, tendem a influenciar mais fortemente elementos de natureza cognitiva do que os de natureza comportamental, os quais tendem a ser mais específicos e circunscritos pelas peculiaridades do objeto, do tipo de ação/comportamento e dos contextos temporais e espaciais. 
As atitudes do consumidor e a propensão à compra de falsificados

A relação entre atitudes e intenções representa um dos principais elos entre os construtos que compõem a Teoria do Comportamento Planejado (Ajzen, 1985; 2005). No que se refere aos estudos sobre o consumo de falsificados, verifica-se uma série de pesquisas empíricas que comprovam a influência das atitudes do consumidor em relação aos produtos falsificados na propensão à compra de tais produtos (Grohmann, Rosa, Nunes, \& Piveta, 2014; Matos \& Ituassu, 2005; Staake, Thiesse, \& Fleisch, 2009). Sendo assim, a seguinte hipótese foi estabelecida:

H4: As atitudes dos consumidores em relação aos produtos falsificados influenciam positivamente a propensão ao seu consumo.

\section{Aspectos Metodológicos}

Tendo em vista os objetivos propostos, optou-se pela realização de um estudo quantitativo, descritivo, com recorte transversal, conduzido por meio de uma Survey. Conforme Malhotra (2012), o processo de amostragem pode ser considerado como não probabilístico, por conveniência, uma vez que se utilizou os contatos dos pesquisadores como ponto de partida para a coleta de dados. O questionário foi programado no aplicativo Survey Monkey, sendo sua versão final validada somente após a realização de um pré-teste junto a 10 respondentes, o que levou a pequenos ajustes nos enunciados das questões. A coleta de dados se deu a partir do disparo do link do questionário eletrônico aos contatos dos pesquisadores, tendo ocorrido entre fevereiro e março de 2017.

O questionário foi do tipo estruturado (Malhotra, 2012), sendo composto por 66 itens. Para mensuração dos valores pessoais utilizou a escala PVQ-40, proposta por Schwartz et al. (2001), já traduzida e validada no Brasil (Tamayo, 2007; Sambiase, Teixeira, \& Bilsky, 2014). A escolha do PVQ-40 se deu pela intenção de utilizar a teoria de Schwartz (1992), avaliando os tipos motivacionais de modo individual, de forma a exigir o mínimo de tempo de preenchimento (Calvosa, 2012).

Para mensuração da propensão à compra de produtos falsificados, utilizou-se a escala desenvolvida por Huang, Lee e Hsun Ho (2004), já testada e validada no contexto brasileiro por Ribeiro (2015). Optou-se por tratar tal escala como propensão à compra de falsificados em detrimento ao termo "intenção", uma vez que os itens que compõem tal construto se mostram mais coerentes com o termo "propensão", a qual, nesse caso, é tomada como uma predisposição à ação. Para medir as orientações éticas deontológica e teleológica optou-se pela escala utilizada por Burns e Kiecker (1995), traduzida para o Português e submetida a um comitê formado por um tradutor profissional e três pesquisadores (um doutor e dois mestres), com fluência na língua inglesa. O questionário também foi composto por 06 (seis) variáveis relativas às características sociodemográficas dos respondentes, a saber: sexo, renda familiar, escolaridade, faixa etária, religião e religiosidade. 
Todos os construtos teóricos de primeira ordem que formam o modelo a ser testado foram mensurados a partir da abordagem reflexiva (Hair, Hult, Ringle, \& Sarstedt, 2014), por meio de uma escala de concordância que varia de 0 (Discordo Totalmente) a 10 (Concordo Totalmente). Exceto no que se refere às dimensões da teoria dos valores pessoais (Schwartz 1992; Schwartz et al., 2012), todas as demais escalas mensuram construtos unidimensionais (Apêndice 1).

No que se refere à religiosidade, cada entrevistado foi solicitado a informar se seguia alguma religião. Dentre os que responderam positivamente, perguntou-se "De zero a dez, o quanto a religião afeta o modo como você se comporta?". Considerando que os respondentes que afirmaram não possuir religião tiveram a nota zero atribuída à variável de religiosidade, o índice de religiosidade utilizado no presente estudo reflete a importância da religião na determinação dos comportamentos dos participantes da amostra.

Dado o interesse não só de testar as hipóteses estabelecidas, mas de analisar o modelo nomológico como um todo, optou-se pela técnica de Modelagem de Equações Estruturais a partir da abordagem dos Mínimos Quadrados Parciais. Hair et al. (2014) afirmam que essa técnica é indicada para testar modelos complexos, em que variáveis latentes atuam ao mesmo tempo tanto como elementos explicativos quanto explicados. Para proceder tal análise utilizou-se o Software SmartPLS versão 3.2.7 (Ringle, Wende \& Becker., 2015).

\section{Análise Dos Resultados}

\section{Análise Exploratória Preliminar}

Ao todo foram obtidos 478 questionários respondidos. Conforme recomendações da European Social Survey para os estudos sobre valores humanos (ESS apud Sambiase et al., 2014), verificou-se a existência de casos em que as respostas se repetiam em $76 \%$ ou mais das perguntas sobre valores pessoais e ética. Ao todo, foram excluídos 25 casos devido à ocorrência do viés de empilhamento (Añaña \& Nique, 2009), caracterizado pela dificuldade de diferenciação dos valores pessoais por meio de uma escala intervalar.

Também foi avaliada a existência de dados ausentes. Ao todo foram identificados 30 casos de respostas ausentes, nos quais utilizou-se o método de substituição pela média da variável (Hair et al., 2009). Não foram encontrados indícios de um processo sistemático de perda de dados, uma vez que as questões que obtiveram maior índice de dados ausentes atingiram o patamar máximo de 1,1\%.

Verificou-se ainda a ocorrência de casos atípicos univariados e multivariados. Considerando o critério de 04 desvios-padrão (Hair et al., 2009), a análise univariada localizou menos de 1\% de respostas atípicas. Já a análise multivariada não identificou nenhum caso atípico, a partir da medida $\mathrm{D}^{2}$ de Mahalanobis (Hair et al., 2009). Vale ressaltar que nenhum caso atípico foi retirado da amostra, por considerar que tais observações são casos válidos 
da população e que sua eliminação poderia limitar a generalidade da análise multivariada, apesar da possível melhora seus resultados (Hair et al., 2009).

O número de entrevistas foi considerado satisfatório uma vez que, conforme recomendações de Hair et al. (2014), a amostra para estudos que utilizam modelagem de equações estruturais deve ser de no mínimo 10 vezes o número de itens utilizados para mensurar o construto formativo com maior número de itens. Como o construto formativo que utilizou mais itens em sua mensuração (Foco Social) possui 13 itens, tem-se que a amostra de 453 casos foi adequada. Além disto, ainda conforme as recomendações dos autores, analisou-se o poder estatístico das análises (Cohen, 1988), considerando o nível de confiança de 99\%. Dado que Hair et al. (2014) indicam que o teste do poder estatístico da análise deve ser igual ou superior a 0,8, tem-se que a amostra obtida pode ser considerada satisfatória, já que o menor índice obtido a partir desse teste foi de 0,92231, para o construto Atitude, no modelo que operacionalizou as dimensões Foco Pessoal e Foco Social dos valores pessoais.

Seguindo as instruções de Hair et al. (2014), verificou-se como se deram as distribuições dos dados, por meio da análise de assimetria e curtose. Como 13 das 60 variáveis utilizadas para mensuração dos construtos teóricos apresentaram distribuições não-normais, optou-se pela utilização da modelagem de equações estruturais a partir da abordagem dos mínimos quadrados parciais (PLS), uma vez que esta não exige que a distribuição dos dados seja normal (Hair et al., 2014).

\section{Avaliação de vieses de método comum}

Considerando a natureza transversal do estudo em tela, o fato de que a coleta ocorreu em um único momento, em que todos os participante responderam tanto às variáveis dependentes quanto às independentes e que o tema discutido pode envolver constrangimento social, algumas medidas foram tomadas para avaliação e minimização da incidência dos vieses de método comum (Podsakoff, MacKenzie, Lee, \& Podsakoff, 2003). Inicialmente os respondentes foram alertados sobre a liberdade para responder livremente ao questionário, não havendo repostas certas ou erradas para nenhuma pergunta. Também foi garantido o anonimato aos respondentes, bem como os itens de cada escala foram randomizados. Por fim, aplicou-se o teste de fator único de Harmam, o qual apontou para a ausência de tal viés, uma vez que 17 (dezessete) fatores com autovalores maiores que 1 emergiram a partir da solução não rotacionada. Vale ressaltar que a capacidade explicativa deste conjunto de fatores foi de apenas 59,2\% da variância dos dados.

\section{Dados Demográficos}

Devido a coleta de dados ter se concentrado no ambiente universitário, predominam, entre os respondentes, jovens de 18 a 30 anos $(72,6 \%)$, mulheres (66\%) e escolaridade superior incompleta (53,6\%). A amostra se concentra na faixa mais alta de renda, uma vez que $43 \%$ apresentam renda familiar acima de 15 salários mínimos (Tabela 02). 
Tabela 02. Caracterização da Amostra

\begin{tabular}{clcc}
\hline & & f & $\%$ \\
\hline \multirow{2}{*}{ Sexo } & Masculino & 154 & $34 \%$ \\
& Feminino & 299 & $66 \%$ \\
\hline \multirow{3}{*}{ Idade } & Até 17 anos & 19 & $4,2 \%$ \\
& De 18 a 30 anos & 329 & $72,6 \%$ \\
& De 31 a 45 anos & 74 & $16,3 \%$ \\
& De 46 a 59 anos & 24 & $5,3 \%$ \\
& 60 anos ou mais & 7 & $1,5 \%$ \\
\hline \multirow{5}{*}{ Renda Familiar } & Até 02 salários mínimos & 20 & $4,4 \%$ \\
& Mais de 02 até 04 salários mínimos & 63 & $13,9 \%$ \\
& Mais de 04 até 08 salários mínimos & 90 & $19,9 \%$ \\
& Mais de 08 até 15 salários mínimos & 85 & $18,8 \%$ \\
& Mais de15 salários mínimos & 195 & $43,0 \%$ \\
\hline \multirow{2}{*}{ Escolaridade } & Fundamental (completo e incompleto) & 4 & $0,9 \%$ \\
& Ensino Médio (completo e incompleto) & 51 & $11,3 \%$ \\
& Superior incompleto & 243 & $53,6 \%$ \\
& Superior Completo & 79 & $17,4 \%$ \\
& Pós-Graduado & 76 & $16,8 \%$ \\
\hline Religião & Católica (6,1) & 249 & $55 \%$ \\
religiosiosidade) & Evangélica (7,7) & 60 & $13,2 \%$ \\
& Espírita (7,5) & 62 & $13,7 \%$ \\
& Agnóstico / Ateu (-) & 65 & $14,3 \%$ \\
& Outras (7,9) & 17 & $3,8 \%$ \\
\hline
\end{tabular}

Fonte: Dados da Pesquisa, 2017

Ainda em análise à tabela 02, tem-se que a maior parte dos respondentes é católica (55\%). Os Agnósticos e Ateus representam 14,3\% da amostra. Já os Espíritas e Evangélicos totalizam 13,7\% e 13,2\%, respectivamente. O índice de religiosidade obteve a média geral de 6,6 pontos para todos os participantes que possuem religião (Tabela 02).

\section{Avaliação do Modelo de Mensuração}

Para avaliação do modelo de mensuração, em coerência com Hair et al. (2014), inicialmente levou-se em consideração a natureza formativa ou reflexiva das variáveis latentes, bem como os procedimentos específicos para mensuração de construtos de alta ordem.

O primeiro modelo analisado envolveu a mensuração individual de cada um dos valores pessoais que compõem o framework teórico de Schwartz (1992). Como todos os construtos que compõem esse modelo são do tipo reflexivos, para verificação das mensurações foram analisadas a validade convergente, a confiabilidade e a validade discriminante. A Confiabilidade 
Composta é o indicador mais adequado para análise da confiabilidade quando se utiliza a abordagem PLS (Hair et al., 2014; Ringle, Silva \& Bido, 2014). Conforme Tenenhaus, Vinzi, Chatelin e Lauro (2005), para análise da confiabilidade de construtos latentes a confiabilidade composta deve ser superior à 0,7. Contudo, para Henseler, Christian e Sinkovics (2009), valores iguais ou superiores a 0,6 podem ser tolerados em estudos exploratórios.

De acordo com Hair et al. (2014), foi verificada a necessidade de exclusão de itens das escalas a partir da análise da confiabilidade, da variância média extraída (AVE) e das cargas fatoriais. A Tabela 03 apresenta os indicadores de qualidade dos construtos em suas configurações finais, após a fase de exclusão de itens. O algoritmo foi calculado considerando as orientações de Hair et al. (2014), com as seguintes configurações: Máximo de Iterações (300); Critério de Parada (10^-7); Weighting Scheme (Path). Já os Bootstrapping`s foram calculados com as seguintes configurações: Subsamples (500); Test Type (Two Tailed); Significance Level (5\%).

Tabela 03. Métricas do Modelo de Mensuração - Construtos de 1ª ordem

\begin{tabular}{lcccc}
\hline \multicolumn{1}{c}{ Construto Teórico } & $\begin{array}{c}\text { Confiabilidade } \\
\text { Composta }\end{array}$ & AVE & No de Itens & Itens Excluídos \\
\hline Autodeterminação & 0,775 & 0,641 & 02 & AUD2; AUD4 \\
Benevolência & 0,745 & 0,508 & 03 & BEN2 \\
Conformidade & 0,771 & 0,532 & 03 & CON3 \\
Estimulação & 0,832 & 0,714 & 02 & EST1 \\
Hedonismo & 0,840 & 0,638 & 03 & - \\
Poder & 0,872 & 0,773 & 02 & P0D1 \\
Realização & 0,770 & 0,634 & 02 & REA2; REA4 \\
Segurança & 0,771 & 0,629 & 02 & SEG1; SEG2; SEG4 \\
Tradição & 0,650 & 0,542 & 02 & TRA2; TRA3 \\
Universalismo & 0,751 & 0,507 & 03 & UNI1; UNI2; UN16 \\
Ética Teleológica & 0,776 & 0,637 & 02 & TE02; TE03 TE04 \\
Ética Deontológica & 0,756 & 0,509 & 03 & DE03; DE04; DE06 \\
Atitude falsificados & 0,841 & 0,569 & 04 & ATF2; ATF5 \\
Propensão à Compra de Falsificados & 0,912 & 0,777 & 03 & - \\
\hline
\end{tabular}

Fonte: Dados da Pesquisa, 2017

Ao analisar os índices de confiabilidade composta e de AVE, verifica-se que todas as medições atingiram os coeficientes mínimos aceitáveis de 0,6 e de 0,5, respectivamente. Já para avaliação da validade discriminante optou-se pelo critério Fornell-Larcker, sugerido por Hair et al. (2014). Conforme os autores, a raiz da AVE de cada construto deve ser maior do que o quadrado da correlação entre os mesmos. Desta forma, ao verificar a Tabela 04 tem-se a confirmação da validade discriminante entre os construtos do modelo. 
Tabela 04. Validade Discriminante

\begin{tabular}{|c|c|c|c|c|c|c|c|c|c|c|c|c|c|c|}
\hline & 1 & 2 & 3 & 4 & 5 & 6 & 7 & 8 & 9 & 10 & 11 & 12 & 13 & 14 \\
\hline 1. Atitude Falsificados & 0,754 & & & & & & & & & & & & & \\
\hline 2. Autodeterminação & $-0,133$ & 0,800 & & & & & & & & & & & & \\
\hline 3. Benevolência & $-0,076$ & 0,221 & 0,713 & & & & & & & & & & & \\
\hline 4. Conformidade & $-0,108$ & 0,043 & 0,225 & 0,729 & & & & & & & & & & \\
\hline 5. Deontológico & $-0,180$ & 0,048 & 0,152 & 0,249 & 0,713 & & & & & & & & & \\
\hline 6. Estimulação & 0,102 & 0,324 & 0,147 & $-0,049$ & $-0,117$ & 0,845 & & & & & & & & \\
\hline 7. Hedonismo & 0,102 & 0,200 & 0,103 & 0,056 & $-0,074$ & 0,454 & 0,799 & & & & & & & \\
\hline 8. PCF & 0,725 & $-0,142$ & $-0,045$ & $-0,080$ & $-0,112$ & 0,042 & 0,019 & 0,881 & & & & & & \\
\hline 9. Poder & $-0,063$ & 0,233 & 0,000 & $-0,014$ & $-0,056$ & 0,224 & 0,121 & $-0,055$ & 0,879 & & & & & \\
\hline 10. Realização & $-0,112$ & 0,255 & 0,004 & 0,028 & $-0,048$ & 0,208 & 0,312 & $-0,055$ & 0,348 & 0,796 & & & & \\
\hline 11. Segurança & $-0,123$ & 0,167 & 0,171 & 0,272 & 0,160 & 0,008 & 0,043 & $-0,095$ & $-0,035$ & 0,049 & 0,793 & & & \\
\hline 12. Teleológico & 0,155 & 0,061 & $-0,058$ & $-0,040$ & $-0,281$ & 0,031 & 0,032 & 0,143 & 0,029 & 0,023 & 0,001 & 0,798 & & \\
\hline 13. Tradição & 0,085 & 0,051 & 0,234 & 0,241 & 0,107 & 0,024 & $-0,002$ & 0,029 & $-0,204$ & $-0,161$ & 0,029 & $-0,020$ & 0,736 & \\
\hline 14. Universalismo & $-0,090$ & 0,151 & 0,420 & 0,285 & 0,204 & 0,078 & 0,131 & $-0,055$ & $-0,146$ & $-0,067$ & 0,168 & 0,007 & 0,304 & 0,712 \\
\hline
\end{tabular}

Fonte: Dados da Pesquisa, 2017

PCF= Propensão à Compra de Falsificados

Considerando a necessidade de acessar os valores pessoais a partir das 04 dimensões teóricas propostas por Schwartz (1992) e das dimensões Foco Social e Foco Pessoal (Schwartz et al., 2012), utilizou-se a abordagem Repetição de Itens para mensuração de construtos de segunda ordem, considerando a configuração Reflexiva-Formativa, apresentada por Hair et al. (2014). De acordo com tais autores, para que tal mensuração seja considerada adequada, deve-se verificar se os itens utilizados para mensuração do construto de segunda ordem são significativos para sua mensuração. Além disto, a relação entre os construtos de primeira e de segunda ordem também deve ser significativa. A Tabela 05 apresenta os resultados de tal avaliação. Nas células referentes aos construtos de primeira ordem, entre parênteses, são apresentados os coeficientes de caminho (CC) e os valores-p (Sig) referentes à sua relação com o construto de segunda ordem ao qual está inserido.

Em análise à Tabela 05 verifica-se que todos os itens utilizados para mensurar as quatro dimensões dos valores pessoais (Modelo B) bem como todos os itens usados para medir o Foco Social e o Foco Pessoal (Modelo C) apresentam significância ao nível de 99\%. Além disto, tem-se que todos os construtos de primeira ordem são significativamente influenciados pelas suas respectivas dimensões de segunda ordem, o que atesta a qualidade das tais mensurações.

Conforme recomendações de Schwartz (1992), também foi analisada a estrutura dos dados relativos à mensuração dos valores pessoais por meio da técnica de Escalonamento Multidimensional, a partir do programa SPSS (V.21). Os índices brutos de stress de $(0,07463$ e 0,06752) se mostram dentro do limite sugerido pelo autor, que devem ser inferiores à 0,2. 
Tabela 05. Métricas do Modelo de Mensuração - Construtos de 2a Ordem

\begin{tabular}{|c|c|c|c|c|c|c|c|c|}
\hline \multirow[b]{2}{*}{ Modelo } & \multicolumn{2}{|c|}{ Construto } & \multirow[b]{2}{*}{ Item } & \multirow[b]{2}{*}{ VIF } & \multicolumn{2}{|c|}{ Outer Weights } & \multicolumn{2}{|c|}{ Confidence Intervals } \\
\hline & $\begin{array}{l}\text { 1a ordem } \\
\text { (CC / Sig) }\end{array}$ & 2a ordem & & & $\begin{array}{l}\text { Original } \\
\text { Sample }\end{array}$ & P Values & $2,50 \%$ & $97,50 \%$ \\
\hline \multirow{24}{*}{ B } & \multirow{2}{*}{$\begin{array}{c}\text { Autodeterminação } \\
(0,125 / 0,023)\end{array}$} & \multirow{7}{*}{ Abertura à Mudança } & AUD1 & 1,221 & 0,192 & 0,000 & 0,150 & 0,230 \\
\hline & & & AUD3 & 1,152 & 0,175 & 0,000 & 0,135 & 0,207 \\
\hline & \multirow{2}{*}{$\begin{array}{c}\text { Estimulação } \\
(0,797 / 0,000)\end{array}$} & & EST2 & 1,394 & 0,255 & 0,000 & 0,231 & 0,280 \\
\hline & & & EST3 & 1,435 & 0,266 & 0,000 & 0,240 & 0,293 \\
\hline & \multirow{3}{*}{$\begin{array}{c}\text { Hedonismo } \\
(0,833 / 0,000)\end{array}$} & & HED2 & 1,279 & 0,194 & 0,000 & 0,162 & 0,222 \\
\hline & & & HED3 & 2,013 & 0,275 & 0,000 & 0,252 & 0,296 \\
\hline & & & HED1 & 1,675 & 0,238 & 0,000 & 0,212 & 0,265 \\
\hline & \multirow{4}{*}{$\begin{array}{c}\text { Poder } \\
(0,871 / 0,000) \\
\text { Realização } \\
(0,795 / 0,000)\end{array}$} & \multirow{4}{*}{ Autopromoção } & POD2 & 1,497 & 0,375 & 0,000 & 0,346 & 0,406 \\
\hline & & & POD3 & 1,489 & 0,375 & 0,000 & 0,349 & 0,403 \\
\hline & & & REA3 & 1,234 & 0,361 & 0,000 & 0,334 & 0,391 \\
\hline & & & REA1 & 1,130 & 0,299 & 0,000 & 0,256 & 0,331 \\
\hline & \multirow{3}{*}{$\begin{array}{c}\text { Benevolência } \\
(0,863 / 0,000)\end{array}$} & \multirow{6}{*}{ Autotranscedência } & BEN1 & 1,287 & 0,337 & 0,000 & 0,302 & 0,373 \\
\hline & & & BEN3 & 1,330 & 0,384 & 0,000 & 0,345 & 0,421 \\
\hline & & & BEN3 & 1,169 & 0,290 & 0,000 & 0,253 & 0,324 \\
\hline & \multirow{3}{*}{$\begin{array}{l}\text { Universalismo } \\
(0,866 / 0,000)\end{array}$} & & UNI4 & 1,402 & 0,312 & 0,000 & 0,277 & 0,349 \\
\hline & & & UNI3 & 1,348 & 0,272 & 0,000 & 0,239 & 0,301 \\
\hline & & & UN15 & 1,121 & 0,281 & 0,000 & 0,249 & 0,312 \\
\hline & \multirow{3}{*}{$\begin{array}{l}\text { Conformidade } \\
(0,871 / 0,000)\end{array}$} & & CON2 & 1,269 & 0,301 & 0,000 & 0,251 & 0,347 \\
\hline & & & CON4 & 1,215 & 0,292 & 0,000 & 0,248 & 0,335 \\
\hline & & & CON1 & 1,173 & 0,242 & 0,000 & 0,155 & 0,303 \\
\hline & \multirow{2}{*}{$\begin{array}{c}\text { Segurança } \\
(0,604 / 0,000)\end{array}$} & Conservação & SEG3 & 1,125 & 0,330 & 0,000 & 0,290 & 0,371 \\
\hline & & & SEG4 & 1,110 & 0,196 & 0,000 & 0,112 & 0,257 \\
\hline & \multirow{2}{*}{$\begin{array}{c}\text { Tradiçãa } \\
(0,518 / 0,000)\end{array}$} & & TRA1 & 1,084 & 0,225 & 0,000 & 0,125 & 0,294 \\
\hline & & & TRA4 & 1,101 & 0,259 & 0,000 & 0,195 & 0,309 \\
\hline \multirow{24}{*}{ C } & Autodeterminação & & AUD1 & 1,298 & 0,162 & 0,000 & 0,126 & 0,195 \\
\hline & $(0,573 / 0,000)$ & & AUD3 & 1,187 & 0,139 & 0,000 & 0,109 & 0,166 \\
\hline & Estimulação & & EST2 & 1,461 & 0,196 & 0,000 & 0,172 & 0,223 \\
\hline & $(0,716 / 0,000)$ & & EST3 & 1,460 & 0,184 & 0,000 & 0,153 & 0,212 \\
\hline & & & HED2 & 1,356 & 0,154 & 0,000 & 0,127 & 0,179 \\
\hline & $\begin{array}{l}\text { Hedonismo } \\
\text { (0724 / } 0000\end{array}$ & Foco Pessoal & HED3 & 2,121 & 0,190 & 0,000 & 0,165 & 0,216 \\
\hline & & & HED1 & 1,692 & 0,163 & 0,000 & 0,136 & 0,188 \\
\hline & Poder & & POD2 & 1,571 & 0,142 & 0,000 & 0,110 & 0,170 \\
\hline & $(0,550 / 0,000)$ & & POD3 & 1,597 & 0,162 & 0,000 & 0,127 & 0,191 \\
\hline & Realização & & REA3 & 1,378 & 0,188 & 0,000 & 0,160 & 0,212 \\
\hline & $(0,665 / 0,000)$ & & REA1 & 1,192 & 0,156 & 0,000 & 0,126 & 0,186 \\
\hline & & & BEN1 & 1,332 & 0,182 & 0,000 & 0,153 & 0,207 \\
\hline & Benevolência & & BEN3 & 1,355 & 0,167 & 0,000 & 0,135 & 0,197 \\
\hline & & & BEN3 & 1,190 & 0,151 & 0,000 & 0,118 & 0,177 \\
\hline & & & UNI4 & 1,445 & 0,180 & 0,000 & 0,152 & 0,203 \\
\hline & $\begin{array}{l}\text { Universalismo } \\
(0,799 \text { / 0.000) }\end{array}$ & & UNI3 & 1,477 & 0,197 & 0,000 & 0,169 & 0,223 \\
\hline & & & UN15 & 1,267 & 0,172 & 0,000 & 0,145 & 0,198 \\
\hline & & Foco Social & CON2 & 1,284 & 0,149 & 0,000 & 0,118 & 0,179 \\
\hline & Conformidade & & CON4 & 1,382 & 0,184 & 0,000 & 0,162 & 0,209 \\
\hline & & & CON1 & 1,179 & 0,127 & 0,000 & 0,094 & 0,157 \\
\hline & Segurança & & SEG3 & 1,134 & 0,108 & 0,000 & 0,061 & 0,140 \\
\hline & $(0,407 / 0,000)$ & & SEG4 & 1,143 & 0,108 & 0,000 & 0,065 & 0,148 \\
\hline & Tradição & & TRA1 & 1,184 & 0,126 & 0,000 & 0,086 & 0,158 \\
\hline & $(0,522 / 0,000)$ & & TRA4 & 1,171 & 0,143 & 0,000 & 0,109 & 0,174 \\
\hline
\end{tabular}

Fonte: Dados da Pesquisa, 2017 
Efeito das variáveis demográficas em relação às atitudes e à propensão de compra de falsificados

Dado o objetivo de identificar as características demográficas dos públicos com atitudes mais ou menos favoráveis ao consumo de falsificados e com maior ou menor propensão à compra de tais produtos, utilizou-se o teste paramétrico de comparação de amostras independentes One-way ANOVA (Malhotra \& Birks, 2007). Apesar da normalidade da distribuição dos dados não ter sido confirmada, em coerência com Bussab e Morettin (2004), optou-se pela utilização de tal teste por sua maior robustez em relação aos não-paramétricos e também por se tratar de uma amostra relativamente grande. Segundo tais autores, de acordo com o Teorema do Limite Central, a distribuição da média de uma amostra tenderá para a normalidade quando esta for superior a 30 observações. A decisão de não incluir tais elementos nos modelos estruturais se justifica pela necessidade de avaliação de três modelos teóricos distintos. Para tal, utilizou-se o software SPSS (V.21), considerando-se o nível de confiança de 95\%.

Tabela 06. Teste de Comparação de Média One-Way ANOVA

\begin{tabular}{lcccc}
\hline \multicolumn{1}{c}{ Variável } & $\begin{array}{c}\text { Atitude em relação a produtos } \\
\text { falsificados }\end{array}$ & Propensão Consumo Falsificados \\
& Sig & Decisão* & Sig & Decisão* \\
\hline Faixa etária & 0,000 & Rejeitar hipótese nula & 0,035 & Rejeitar hipótese nula \\
Sexo & 0,721 & Reter hipótese nula & 0,128 & Reter hipótese nula \\
Religião & 0,198 & Reter hipótese nula & 0,359 & Reter hipótese nula \\
Escolaridade & 0,000 & Rejeitar hipótese nula & 0,040 & Rejeitar hipótese nula \\
Renda Familiar & 0,002 & Rejeitar hipótese nula & 0,000 & Rejeitar hipótese nula \\
\hline
\end{tabular}

Fonte: Dados da Pesquisa, 2017

*As hipóteses nulas preveem que a distribuição da medida é igual entre os diferentes grupos comparados.

Os resultados apontam para a existência de diferenças significativas entre as faixas de renda familiar, os níveis de escolaridade e a faixas etárias, no que se refere às atitudes em relação aos produtos falsificados e à propensão à compra de falsificados (ver Tabela 06).

A Tabela 07 apresenta a média das atitudes e da propensão à compra de falsificados por segmento, considerando os agrupamentos que se mostraram distintos em relação a tais índices. No que se refere à idade, tanto as atitudes quanto a propensão à compra de falsificados são maiores entre os jovens. Além disto, tanto no que se refere à escolaridade quanto à renda familiar, os estratos superiores apresentam menor propensão à compra de falsificados, bem como atitudes menos favoráveis a tal comportamento. 
Tabela 07. Média de Propensão à compra de falsificados, por segmento

\begin{tabular}{clcccc}
\hline \multirow{2}{*}{ Critério } & \multicolumn{1}{c}{ Segmento } & \multicolumn{2}{c}{$\begin{array}{c}\text { Atitudes em relação aos falsificados } \\
\text { Média }\end{array}$} & \multicolumn{2}{c}{ Propensão à compra de falsificados } \\
& Desvio Padrão & Média & Desvio Padrão \\
\hline \multirow{5}{*}{ Renda Familiar } & Até 02 SM & 2,28 & 1,00 & 2,73 & 1,14 \\
& De 02 a 04 SM & 2,22 & 0,83 & 2,80 & 1,10 \\
& De 04 a 08 SM & 2,29 & 0,97 & 2,65 & 1,18 \\
& De 08 a 15 SM & 2,17 & 0,84 & 2,21 & 1,16 \\
& 15 SM ou mais & 1,97 & 0,82 & 2,15 & 1,19 \\
& Fundamental & 2,37 & 0,85 & 2,50 & 1,03 \\
& Médio & 2,30 & 0,88 & 2,67 & 1,22 \\
Escolaridade & 2,23 & 0,88 & 2,46 & 1,21 \\
& Superior incompleto & 1,96 & 0,78 & 2,23 & 1,08 \\
& Superior completo & 1,80 & 0,83 & 2,09 & 1,17 \\
& Pós-graduado & 2,66 & 0,88 & 2,95 & 1,00 \\
& Até 17 anos & 2,19 & 0,87 & 2,43 & 1,21 \\
& De 18 a 30 anos & 1,88 & 0,81 & 2,15 & 1,14 \\
& De 31 a 45 anos & 1,65 & 0,78 & 2,23 & 1,15 \\
& De 46 a 59 anos & 1,57 & 0,83 & 1,67 & 0,88 \\
\hline
\end{tabular}

Fonte: Dados da Pesquisa, 2017

Para verificar a relação entre a importância da religião e os construtos relacionados ao consumo de produtos falsificados, utilizou-se o Teste de Correlação de Spearman (Tabela 08), uma vez que este não exige a normalidade da distribuição dos dados (Malhotra \& Birks, 2007).

Tabela 08. Relação da Importância da Religião com Atitudes e Intenção

\begin{tabular}{cccc}
\hline \multicolumn{2}{c}{ Teste de correlação (Spearman) } & Atitudes - Produtos Falsificados & Propensão à Compra de Falsificados \\
\hline \multirow{2}{*}{ Importância da Religião } & Coef. & $-0,172$ & $-0,66$ \\
\cline { 2 - 4 } & Sig & 0,000 & 0,158 \\
\hline
\end{tabular}

Fonte: Dados da Pesquisa, 2017

Adotando-se o nível de confiança de 95\%, os resultados indicam a existência de uma relação significativa entre a importância da religião e as atitudes em relação aos falsificados. Apesar do coeficiente -0,172 indicar uma relação fraca (Cohen, 1988), tem-se que quanto maior a importância da religião, menos favoráveis são as atitudes em relação aos falsificados.

\section{Avaliação do Modelo Estrutural}

Dado o interesse em avaliar a relação entre os valores pessoais, em seus diferentes níveis, e os construtos relacionados ao consumo de falsificados, de modo coerente com a Estratégia de Modelos Concorrentes (Hair et al, 2009), foi necessário testar três modelos estruturais. O primeiro considerou os valores pessoais mensurados individualmente (Modelo A), o segundo 
(Modelo B) avaliou as quatro dimensões teóricas propostas por Schwartz (1992). Já o terceiro (Modelo C) considerou as dimensões Foco Social e Foco Pessoal propostas por Schwartz et al. (2012). Deve-se ressaltar que a análise das dimensões Foco Social e Foco Pessoal se deu a partir do reconhecimento da compatibilidade entre a teoria original (Schwartz, 1992) e a teoria refinada (Schwartz et al., 2012), em consonância com as colocações de Torres et al. (2016). A Tabela 09 apresenta os resultados dos três modelos estruturais testados.

Tabela 09. Modelos Estruturais - Ética, Valores e Falsificados

\begin{tabular}{|c|c|c|c|c|c|}
\hline Modelo & Variável Independente & Variável Dependente & $\mathrm{CC}$ & Sig & $\mathrm{R}^{2}$ \\
\hline \multirow{13}{*}{ Modelo A } & Autodeterminação (p) & Atitude Falsificados & $-0,136$ & 0,006 & \multirow{12}{*}{$12,8 \%$} \\
\hline & Benevolência (s) & Atitude Falsificados & $-0,021$ & 0,739 & \\
\hline & Conformidade (s) & Atitude Falsificados & $-0,056$ & 0,278 & \\
\hline & Estimulação (p) & Atitude Falsificados & 0,109 & 0,035 & \\
\hline & Hedonismo (p) & Atitude Falsificados & 0,131 & 0,009 & \\
\hline & Poder (p) & Atitude Falsificados & $-0,029$ & 0,552 & \\
\hline & Realização (p) & Atitude Falsificados & $-0,120$ & 0,013 & \\
\hline & Segurança (s) & Atitude Falsificados & $-0,057$ & 0,258 & \\
\hline & Tradição (s) & Atitude Falsificados & 0,125 & 0,088 & \\
\hline & Universalismo (s) & Atitude Falsificados & $-0,094$ & 0,164 & \\
\hline & Ética Deontológica & Atitude Falsificados & $-0,089$ & 0,065 & \\
\hline & Ética Teleológica & Atitude Falsificados & 0,134 & 0,001 & \\
\hline & Atitude Falsificados & PCF & 0,725 & 0,000 & $52,6 \%$ \\
\hline \multirow{7}{*}{ Modelo B } & Abertura à Mudança (p) & Atitude Falsificados & 0,125 & 0,023 & \multirow{6}{*}{$7,3 \%$} \\
\hline & Autopromoção (p) & Atitude Falsificados & $-0,161$ & 0,004 & \\
\hline & Conservação (s) & Atitude Falsificados & $-0,070$ & 0,161 & \\
\hline & Autotranscedência (s) & Atitude Falsificados & $-0,056$ & 0,324 & \\
\hline & Ética Deontológica & Atitude Falsificados & $-0,120$ & 0,020 & \\
\hline & Ética Teleológica & Atitude Falsificados & 0,114 & 0,008 & \\
\hline & Atitude Falsificados & PCF & 0,725 & 0,000 & $52,6 \%$ \\
\hline \multirow{5}{*}{ Modelo C } & Foco Pessoal & Atitude Falsificados & $-0,016$ & 0,757 & \multirow{4}{*}{$4,7 \%$} \\
\hline & Foco Social & Atitude Falsificados & $-0,051$ & 0,296 & \\
\hline & Ética Deontológica & Atitude Falsificados & $-0,135$ & 0,013 & \\
\hline & Ética Teleológica & Atitude Falsificados & 0,116 & 0,006 & \\
\hline & Atitude Falsificados & PCF & 0,725 & 0,000 & $52,6 \%$ \\
\hline
\end{tabular}

Fonte: Dados da Pesquisa, 2017

PCF $=$ Propensão à Compra de Falsificados

Em análise à Tabela 09, verifica-se que as atitudes dos consumidores em relação aos falsificados influenciam significativamente a propensão à compra de tais produtos, o que confirma a Hipótese 4. Dado o $\mathrm{R}^{2}$ de $52,6 \%$, verifica-se que a capacidade explicativa das atitudes deve ser considerada forte (Cohen, 1988). 
A influência da racionalidade teleológica nas atitudes em relação ao consumo de falsificados se mostra significativa e positiva em todos os modelos, o que confirma a Hipótese 2. Vale mencionar que as Hipóteses 2 e 4 são confirmadas considerando-se o nível de confiança de 99\%, nos três modelos avaliados. Sobre a racionalidade Deontológica, verifica-se que os modelos B e $C$ revelam a existência de uma relação negativa entre esse construto e tais atitudes, ao nível de confiança de 95\%. No que se refere ao Modelo A, essa relação pode ser considerada significativa somente quando se adota o nível de confiança de 90\%. Tais resultados confirmam a Hipótese 1.

No que se refere à influência dos valores pessoais nas atitudes em relação ao consumo de falsificados, tem-se que no nível dos tipos motivacionais (Modelo A) os resultados apontam para relações significativas, considerando-se o nível de confiança de 95\%, entre tais atitudes e os tipos motivacionais Autodeterminação, Hedonismo, Realização e Estimulação. Tais resultados confirmam a Hipótese 3. Vale mencionar que enquanto os tipos motivacionais Autodeterminação e Realização se relacionam negativamente com as atitudes, os tipos Hedonismo e Estimulação se mostram positivamente relacionados com tal construto (Tabela 09).

Sobre as dimensões teóricas propostas por Schwartz (1992; 1994) e Schwartz et al., (2012), os resultados apontam para a existência de relações significativas entre as dimensões Autopromoção e Abertura à Mudança e as atitudes em relação ao consumo de falsificados, considerando os níveis de confiança de 99\% e 95\%, respectivamente (Modelo B). A análise da relação entre as dimensões teóricas Foco Pessoal e Foco Social e as atitudes em relação ao consumo de falsificados (Modelo C) revela a ausência de relação significativas.

Considerando que os modelos avaliados se diferem em termos de abordagem reflexiva e formativa, tem-se que as medidas de avaliação dos seus ajustes globais não podem ser comparadas, uma vez que os critérios que se aplicam a um tipo de mensuração não devem ser aplicados a outra (Hair et al., 2014). Sendo assim, para comparação dos três modelos testados, optou-se pela análise da raiz da média dos Coeficientes de Determinação de Pearson $\left(R^{2}\right)$, em coerência com as proposições de Wetzels, Odekerken-Schröder e Van Oppen . (2009). Dados os resultados da análise (Modelo $A=0,572$; Modelo $B=0,547$; Modelo $C=0,536$ ), tem-se que o modelo que melhor explica os construtos relacionados ao consumo de produtos falsificados é o que operacionalizou os tipos motivacionais em separado (Modelo A).

\section{Conclusões e Considerações Finais}

Buscando identificar os elementos que influenciam as atitudes e a propensão à compra de produtos falsificados, o presente estudo confirmou a relação entre tais construtos e as características sócio demográficas, os valores pessoais e as racionalidades éticas utilizadas pelos consumidores. De modo geral, os resultados demonstram que os jovens e os indivíduos com menor nível de escolaridade e renda familiar são os grupos que apresentam atitudes mais favoráveis ao consumo de falsificados, bem como são os que apresentam maior propensão ao seu consumo. 
Apesar de não haver relação entre a religião adotada pelo indivíduo e as atitudes ou a propensão à compra de falsificados, o que é coerente com os estudos de Queiroz e Souza (2016) e de Santos et al. (2017), verifica-se que a religiosidade influencia negativamente as atitudes em relação ao consumo de falsificados, o que corrobora com os achados de Wagner e Sanders (2001). Sendo assim, conclui-se que não é a religião que influencia o consumo de falsificados, mas sim a importância que a religião assume para cada indivíduo.

No que se refere às racionalidades éticas, os resultados indicam que enquanto o pensamento deontológico influencia negativamente as atitudes em relação ao consumo de falsificados, racionalidades teleológicas influenciam positivamente tais atitudes. Esses achados corroboram com as colocações de Nill e Shultz (1996) e com os achados de Rabelo et al. (2016). Sendo assim, tem-se, sob o ponto de vista da moral e dos princípios que guiam os consumidores, que o consumo de falsificados tende a ser percebido como um comportamento reprovável. Já sob o ponto de vista da análise utilitarista sobre esse comportamento, tem-se que os respondentes tendem a entender o consumo de falsificados como algo aceitável. Tais resultados se mostram valiosos quando se busca compreender os elementos que inibem ou estimulam o consumo de falsificados. A partir de tais achados é possível afirmar que o combate ao consumo de falsificados poderá ser mais eficiente se demonstrar como tal comportamento fere as leis, as normas e os valores sociais de tal comunidade (argumento deontológico), além de demonstrar que os danos causados por tal consumo podem atingir o próprio consumidor, bem como as pessoas e organizações próximas a ele (argumento teleológico). A influência positiva entre a racionalidade teleológica e as atitudes em relação aos falsificados aponta para a prevalência da percepção de que é vantajoso consumir tais produtos, ao menos na esfera individual.

No que concerne aos valores pessoais, os resultados demonstram que enquanto alguns tipos motivacionais estimulam o consumo de falsificados, outros o inibem. Coerentes com a racionalidade teleológica (Andrade et al., 2017), os valores Estimulação e Hedonismo trazem em comum uma orientação individualista (Schwartz et al, 2012) e se mostram como os únicos tipos motivacionais estimulados exclusivamente por necessidades biológicas do indivíduo (Schwartz, 1992). De fato, quando se pensa em indivíduos que se orientam intensamente pela busca de prazer e gratificação individual (Hedonismo) e aqueles que buscam excitação, novidades e desafios ao longo da vida (Estimulação), torna-se compreensível o consumo de produtos falsificados, principalmente quando se ignora os potenciais efeitos maléficos de tal comportamento. Tais achados também se mostram coerentes com as proposições de Reis Junior e Torres (2018).

Por outro lado, ainda que associados a uma perspectiva individualista, pode-se interpretar que os consumidores que se motivam intensamente pelos valores Autodeterminação e Realização rejeitam o consumo de falsificados, seja pela independência de pensamento e ação, o que os levaria a não se sentirem impelidos a seguir determinados padrões de consumo (Autodeterminação), ou por entenderem que o consumo de falsificados representa o fracasso do indivíduo enquanto consumidor, uma vez que o mesmo não seria capaz de adquirir o original (Realização). Já em análise 
às fontes de motivação apresentadas por Schwartz (1994), tem-se que, em comum, tanto a Realização quanto a Autodeterminação são tipos motivacionais motivados pela interação social.

No que se refere ao continuum motivacional de Schwartz (1992; 2012), os resultados demonstram que a relação entre os valores pessoais e os comportamentos dos indivíduos nem sempre se mostrarão lineares e fiéis ao esquema teórico proposto pelo autor. Apesar da confirmação das relações intrínsecas entre os tipos motivacionais e as dimensões da teoria de valores, o antagonismo previsto entre tais elementos foi incapaz de determinar a direção das relações de um tipo motivacional ou de uma dimensão de valores, a partir da análise de seu antagonista.

Considerando as limitações do presente estudo, sugere-se, para o avanço do conhecimento sobre a compra e o consumo de produtos falsificados, a realização de investigações que sejam capazes de analisar e comparar como os consumidores se comportam em relação a diferentes categorias de produtos falsificados. Em coerência com a teoria de Hunt e Vitell (2006), recomenda-se a realização de novos estudos para identificação e compreensão dos consumidores que percebem e que não percebem dilemas éticos relacionados ao consumo de falsificados. Além disto, ainda com base em tais autores, propõe-se operacionalizar as racionalidades deontológicas e teleológicas em conjunto, e não em separado, como no caso do presente estudo. Já em relação aos valores pessoais, sugere-se a aplicação da escala refinada dos valores pessoais (Schwartz et al., 2012), uma vez que, conforme os autores, tal escala propiciaria mais capacidade heurística e poder explanatório, além de ser apropriada para mensuração das dimensões Foco Pessoal e Foco Social. Outra ponto de interesse para estudos futuros reside na análise de relações diretas ou mediadas entre a propensão à compra de falsificados e os valores pessoais e as racionalidades éticas. Ainda em relação aos valores pessoais, sugere-se a realização de um estudo de natureza qualitativa, para identificação e compreensão mais aprofundada sobre o processo cognitivo relacionado ao consumo de falsificados e aos valores que motivam e inibem tal comportamento.

\section{Referências}

Ajzen, I. (1985). From intentions to action: A theory of planned behavior. In J. Kuhl \& J. Beckman (Eds.), Action control: From cognitions to behaviors (pp. 11-39). New York: Springer.

Ajzen, I. (2005). Attitudes, personality, and behavior. 2a ed., New York: Open University Press.

Añaña, E. S., \& Nique, W. M. (2009). O valor dos valores: avaliação de uma marca global por meio dos diversos brasis culturais. Revista de Administração Mackenzie (Mackenzie Management Review), 10(3), 153-181.

Andrade, M. L., \& Leite, R. S. (2017, outubro). Teoria Dos Valores Pessoais Em Marketing: Um Estudo Bibliométrico Sobre As Publicações Nacionais. Anais do Encontro Nacional da Associação do Programas de Pós-Graduação em Administração (EnAnpad 2017), São Paulo, SP, Brasil, XLI. 
Andrade, M. L., Leite, R. S., Diniz, W. V., Costa, K. C., \& Ibrahim, S. T. C. A. (2017, novembro) Processos Axiológicos: Proposta de (Re)Integração das Teorias sobre Ética e Valores Pessoais. Anais do XX SEMEAD Seminários Em Administração, São Paulo, SP, Brasil, 20.

Andrade, M. L., Leite, R. S., \& Salvador, S. (2018) Falsificado sim, mas de coração!: Uma investigação interpretativa sobre $o$ ato de presentear com produtos falsificados. In M. R. Pinto \& G. L. Batinga (Orgs.). Cultura e Consumo no Brasil: estado atual e novas perspectivas. Editora PUC-MG: Belo Horizonte.

Araújo, B. F. V. B., Bilsky, W., \& Oliveira Moreira, L. M. C. (2012). Valores pessoais como antecedentes da adaptação transcultural de expatriados. Revista de Administração Mackenzie, 13(3), 69-95.

Baker, J. A. (2008) Virtue Ethics. In R. W. Kolb (Ed.). Encyclopedia of Business Ethics and Society (pp. 2191-2198). Thousand Oaks: SAGE Publications.

Bilsky, W. (2009). A estrutura de valores: sua estabilidade para além de instrumentos, teorias, idade e culturas. Revista de Administração Mackenzie, 10(3), 12-33.

Bloch, P. H., Bush, R. F., \& Campbell, L. (1993). Consumer "accomplices" in product counterfeiting: a demand side investigation. Journal of consumer marketing, 10(4), 27-36.

Burns, J. O., \& Kiecker, P. (1995). Tax practitioner ethics: An empirical investigation of organizational consequences. The Journal of the American Taxation Association, 17(2), 20.

Bussab, W. O., \& Morettin, P. A. (2004) Estatística básica. 5. ed. São Paulo: Saraiva.

Calvosa, M. V. D. (2012, novembro). Uma pesquisa bibliométrica sobre valores pessoais: a análise global de instrumentos de mensuração de valores pessoais. Anais do XXVII Simpósio De Gestão De Inovação Tecnológica da Associação do Programas de Pós-Graduação em Administração (2012), Salvador, BA, Brasil, XXVII.

Casali, R. R. B., Paes, T. A. A., Machado, P. A., Medeiros, L. C., \& Aragão, A. J. (2010). Pirataria de Software: Uma Análise da Relação entre Comportamento Ético, Atitude e Intenção do Consumidor. Anais do XXIV Encontro da ANPAD, Rio de Janeiro, RJ, 24.

Chaudhry, P. E., \& Zimmerman, A. (2009). The economics of counterfeit trade: Governments, consumers, pirates and intellectual property rights. Heidelberg: Springer.

Cheung, W. L., \& Prendergast, G. (2006). Buyers' perceptions of pirated products in China. Marketing Intelligence \& Planning, 24(5), 446-462.

Clavo, L. C. (2008). Aristóteles para Executivos: como a filosofia ajuda na gestão empresarial. São Paulo: Globo.

Cohen, J. (1988). Statistical power analysis for the behavioral sciences. 2nd ed. New York: Psychology Press.

Conselho Nacional de Combate à Pirataria (CNPC). Brasil Original. Brasília (2011). Recuperado em 25 março, 2018 , de http://portal.mj.gov.br/main. asp?Team=\%7B1450A8F5-90F9-4EE7-B58C-36EA406FD360\%7D.

Cordell, V. V., Wongtada, N., \& Kieschnick, R. L. (1996). Counterfeit purchase intentions: role of lawfulness attitudes and product traits as determinants. Journal of Business Research, 35(1), 41-53. 
Cotrin, G. (2002). Fundamentos de Filosofia: história e grandes temas. 15a ed. São Paulo, Saraiva.

Eisend, M., \& Schuchert-Güler, P. (2006). Explaining counterfeit purchases: A review and preview. Academy of Marketing Science Review, 12, 1-26.

Eisend, M., Hartmann, P., \& Apaolaza, V. (2017). Who buys counterfeit luxury brands? A meta-analytic synthesis of consumers in developing and developed markets. Journal of International Marketing, 25(4), 89-111.

Furnham, A., \& Valgeirsson, H. (2007). The effect of life values and materialism on buying counterfeit products. The Journal of Socio-Economics, 36(5), 677-685.

Gentry, J., Putrevu, S., Shutz I., \& Clifford, C., S. (2001) How now Ralf Lauren? The separation of brand and product in a counterfeit culture. Advances in Consumer Research, 28(1), 258-265. Recuperado em 04 setembro, 2014, de http://www. acrwebsite.org/search/view-conference-proceedings.aspx?ld=8485

Grossman, G. M., \& Shapiro, C. (1988). Foreign counterfeiting of status goods. The Quarterly Journal of Economics, 103(1), 79-100.

Gupta, P. B., Gould, S. J., \& Pola, B. (2004). "To pirate or not to pirate": A comparative study of the ethical versus other influences on the consumer's software acquisition-mode decision. Journal of Business Ethics, 55(3), 255-274.

Grohmann, M. Z., Rosa, A. C., Nunes, J. D. O., \& Piveta, M. N. (2014). Comportamento dos jovens em relação à pirataria digital: Uma pesquisa com estudantes do ensino médio público. Estudos do ISCA, (9).

Hair, J. F., Black, W. C., Babin, B. J., Anderson, R. E., \& Tatham, R. L. (2009). Análise multivariada de dados. Porto Alegre: Editora Bookman.

Hair J. F. Jr., Hult, G. T. M., Ringle, C. \& Sarstedt, M. (2014). A primer on partial least squares structural equation modeling (PLS-SEM). Los Angeles: Sage Publications.

Henseler, J., Ringle, C. M., \& Sinkovics, R. R. (2009). The use of partial least squares path modeling in international marketing. Advances in International Marketing 20, 277-319.

Huang, J. H., Lee, B. C., \& Hsun Ho, S. (2004). Consumer attitude toward gray market goods. International Marketing Review, 21(6), 598-614.

Hunt, S. D., \& Vitell, S. (1986). A general theory of marketing ethics. Journal of Macromarketing, 6(1), 5-16.

Hunt, S. D., \& Vitell, S. J. (1993). The General Theory of Marketing Ethics: A Retrospective and Revision. Ethics in Marketing 775-784.

Hunt, S. D., \& Vitell, S. J. (2006). The general theory of marketing ethics: A revision and three questions. Journal of Macromarketing, 26(2), 143-153.

Kamakura, W. A., \& Mazzon, J. A. (1991). Value segmentation: A model for the measurement of values and value systems. Journal of Consumer Research, 18(2), 208-218

Kluckhohn, C. (1951). Values and value-orientations in the theory of action: An exploration in definition and classification. In T. Parsons \& E. Shils (Eds.), Toward a general theory of action (pp. 388-433). Cambridge. MA: Harvard University Press.

Lau, K. W. (2007). Interaction effects in software piracy. Business Ethics: A European Review, 16(1), 34-47. 
Lee, S.H., \& Yoo, B. (2009). A review of determinants of counterfeiting and piracy and the proposition for future research. Korean Journal of Policy Studies, 24(1), 1-38.

Malhotra, N. K. (2012). Pesquisa de marketing: uma orientação aplicada. Porto Alegre: Bookman.

Malhotra, N. K., \& Birks, D. F. (2007). Marketing Research: An Apllied approach. $3^{\text {a }}$ ed. Harlow: Prentice Hall.

Matos, C., \& Ituassu, C. (2005) Comportamento do consumidor de produtos piratas: os fatores influenciadores das atitudes e das intenções de compra. Anais do Encontro Nacional da Associação do Programas de Pós-Graduação em Administração (EnAnpad 2005), Brasília, DF, Brasil, XXIX.

Morin, E. (2007) O Método: Ética. Tradução: Juremir Machado Da Silva. 3a ed. Porto Alegre: Sulina.

Munson, J. M., \& McQuarrie, E. F. (1988). Shortening the Rokeach value survey for use in consumer research. NA-Advances in Consumer Research, 5(1), 381-386.

Musser, S. J., \& Orke, E. A. (1992). Ethical value systems: A typology. The journal of applied behavioral science, 28(3), 348-362.

Nia, A., \& Zaichkowsky, J. L. (2000). Do counterfeits devalue the ownership of luxury brands?. Journal of Product \& Brand Management, 9(7), 485-497.

Nill, A., \& Shultz, C. J. (1996). The scourge of global counterfeiting. Business Horizons, 39(6), 37-42.

Nill, A., \& Shultz, C. J. (2009). Global software piracy: Trends and strategic considerations. Business Horizons, 52(3), 289-298.

OECD/EUIPO. (2016). Trade in Counterfeit and Pirated Goods: Mapping the Economic Impact, OECD Publishing, Paris.

Passos, E. (2006). Ética nas organizações. São Paulo: Atlas.

Patrus-Pena, R., \& Castro, P. (2010). Ética nos Negócios. Condições, Desafios e Riscos. São Paulo: Editora Atlas.

Penz, E., \& Stottinger, B. (2005). Forget the 'real' thing - Take the copy! An explanatory model for the volitional purchase of counterfeit products. Advances in Consumer Research, 32(1), 568-76.

Pires, M. B. (2008). Estudo dos valores de consumidores de produtos piratas e de consumidores de produtos originais. Trabalho de Conclusão de Curso. (Especialização em Administração) Universidade Federal do Rio Grande do Sul, Porto Alegre, RS, Brasil.

Podsakoff, P. M., MacKenzie, S. B., Lee, J. Y., \& Podsakoff, N. P. (2003). Common method biases in behavioral research: A critical review of the literature and recommended remedies. Journal of applied psychology, 88(5), 879.

Prendergast, G., Hing Chuen, L., \& Phau, I. (2002). Understanding consumer demand for non-deceptive pirated brands. Marketing Intelligence \& Planning, 20(7), 405-416.

Queiroz, A. S., \& Souza, M. J. B. (2016). Consumo de Luxo falsificado no Segmento Jovem. Anais do XL ENANPAD, Costa do Sauipe, BA, Brasil, XL.

Rabello, R. F., Leite, R. S., \& Gonçalves Filho, C. (2016) Consumo de Falsificados: Analisando a Influência da Ética e dos Riscos. Anais do XL ENANPAD, Costa do Sauipe, BA, Brasil, XL. 
Reis Junior, F. N. D. (2018) Luz, câmera, falsificação: proposta de um modelo explicativo para consumo de produtos de luxo falsificado. Tese Doutorado, Universidade de Brasília, Brasília, DF, Brasil.

Reis Junior, F. N. D., \& Torres, C. (2018). As aparências se atraem: valores culturais e consumo de produtos de moda falsificados. Revista Thema, 15(1), 119-132.

Ribeiro, P. D. (2015) Vergonha e Comportamento de Consumo de Produtos Falsificados. Dissertação de Mestrado (Administração de Empresas). FGV, São Paulo, SP, Brasil.

Ringle, C. M., Silva, D., \& Bido, D. D. S. (2014). Modelagem de equações estruturais com utilização do SmartPLS. REMark, 13(2), 54.

Ringle, C. M., Wende, S., \& Becker, J.M. (2015). "SmartPLS 3." Boenningstedt: SmartPLS GmbH. Recuperado em 22 outubro, 2017, de http://www.smartpls.com.

Rohan, M. J. (2000). A rose by any name? The values construct. Personality and Social Psychology review, 4(3), 255-277.

Rokeach, M. (1973) The Nature of Human Values. New York: Free press.

Santos, M. F., Gonçalves Filho, C., \& Falce, J. L. (2017). Entendendo a Compra de Produtos Piratas: a Influência das Estratégias de Negação e Ética do Consumidor. Revista Brasileira de Pesquisas de Marketing, Opinião e Mídia, 10(2), 239-265.

Schwartz, S. H. (1992) Universals in the content and structure of values: Theoretical advances and empirical tests in 20 countries. Advances in Experimental Social Psychology, 25(1), 1-65.

Schwartz, S. H. (1994). Are there universal aspects in the structure and contents of human values?. Journal of social issues, 50(4), 19-45.

Schwartz, S. H., Melech, G., Lehmann, A., Burgess, S., Harris, M., \& Owens, V. (2001). Extending the cross-cultural validity of the theory of basic human values with a different method of measurement. Journal of cross-cultural psychology, 32(5), 519-542.

Schwartz, S. H., Cieciuch, J., Vecchione, M., Davidov, E., Fischer, R., Beierlein, C., ... \& Dirilen-Gumus, O. (2012). Refining the theory of basic individual values. Journal of Personality and Social Psychology, 103(4), 663.

Sambiase, M. F., Teixeira, M. L. M., Bilsky, W., Araujo, B. F. V. B., \& Domenico, S. M. R. (2014). Confrontando estruturas de valores: um estudo comparativo entre PVQ-40 e PVQ-21. Psychology, 27(4), 728-739.

Simon, H. A. (1972). Theories of bounded rationality. Decision and Organization, 1(1), 161-176.

Solomon, S. L., \& O'Brien, J. A. (1990). The effect of demographic factors on attitudes toward software piracy. Journal of Computer Information Systems, 30(3), 40-46.

Staake, T., Thiesse, F., \& Fleisch, E. (2009). The emergence of counterfeit trade: a literature review. European Journal of Marketing, 43(3/4), 320-349.

Staake, T., Thiesse, F., \& Fleisch, E. (2012). Business strategies in the counterfeit market. Journal of Business Research, 65(5), 658-665.

Strehlau, S. (2004) O luxo falsificado e suas formas de consumo. Tese (Doutorado em Administração). Fundação Getúlio Vargas, Escola de Administração de Empresas de São Paulo, São Paulo. 307 f. 
Swami, V., Chamorro-Premuzic, T., \& Furnham, A. (2009). Faking it: Personality and individual difference predictors of willingness to buy counterfeit goods. The Journal of Socio-Economics, 38(5), 820-825.

Tamayo, A. (2007). Hierarquia de valores transculturais e brasileiros. Psicologia: teoria e pesquisa, 23 (Special), 7-15.

Tamayo, A., \& Porto, J. B. (2009). Validação do questionário de perfis de valores (QPV) no Brasil. Psicologia: Teoria e Pesquisa, 25(3), 369-376.

Tang, F., Tian, V. I., \& Zaichkowsky, J. (2014). Understanding counterfeit consumption. Asia Pacific Journal of Marketing and Logistics, 26(1), 4-20.

Tenenhaus, M., Vinzi, V. E., Chatelin, Y. M., \& Lauro, C. (2005). PLS path modeling. Computational statistics \& data analysis, 48(1), 159-205.

Torres, C. V., Schwartz, S. H., \& Nascimento, T. G. (2016). A Teoria de Valores Refinada: associações com comportamento e evidências de validade discriminante e preditiva. Psicologia USP, 27(2), 341-356.

Triandis, H. C., \& Gelfand, M. J. (1998). Converging measurement of horizontal and vertical individualism and collectivism. Journal of personality and social psychology, 74(1), 118.

Van Kempen, L. (2003). Fooling the eye of the beholder: deceptive status signalling among the poor in developing countries. Journal of International Development, 15(2), 157-177.

Vazquez, A. S. (2007) Ética. $29^{a}$ ed. Rio de Janeiro: Civilização Brasileira.

Vida, I., Kos Koklic, M., Kukar-Kinney, M., \& Penz, E. (2012). Predicting consumer digital piracy behavior: The role of rationalization and perceived consequences. Journal of Research in Interactive Marketing, 6(4), 298-313.

Vinson, D. E., Scott, J. E., \& Lamont, L. M. (1977). The role of personal values in marketing and consumer behavior. The Journal of Marketing, 41(2), 44-50.

Vitell, S. J., \& Muncy, J. (1992). Consumer ethics: An empirical investigation of factors influencing ethical judgments of the final consumer. Journal of Business Ethics, 11(8), 585-597.

Vitell, S. J., \& Muncy, J. (2005). The Muncy-Vitell consumer ethics scale: A modification and application. Journal of Business Ethics, 62(3), 267-275.

Wagner, S. C., \& Sanders, G. L. (2001). Considerations in ethical decision-making and software piracy. Journal of Business Ethics, 29(1), 161-167.

Wetzels, M., Odekerken-Schröder, G., \& Van Oppen, C. (2009). Using PLS path modeling for assessing hierarchical construct models: Guidelines and empirical illustration. MIS quarterly, 33(1), 177-195. 


\section{Apêndice 01}

\section{Itens para Mensuração das Variáveis Latentes}

Instrumento de Coleta de Dados

\begin{tabular}{|c|c|c|}
\hline Construto & ID & Item \\
\hline & ATF1 & Comprar produtos falsificados é normal \\
\hline & ATF2 & Considerando o preço, eu tenho preferência por produtos falsificados \\
\hline Atitude & ATF3 & Eu gosto de comprar produtos falsificados \\
\hline \multirow[t]{3}{*}{ Falsificados } & ATF4 & Comprar produtos falsificados geralmente beneficia o consumidor \\
\hline & ATF5 & Comprar produtos falsificados não é errado \\
\hline & ATF6 & Em geral, comprar produtos falsificados é a melhor alternativa \\
\hline \multirow{3}{*}{$\begin{array}{l}\text { Propensão de Compra } \\
\text { Falsificados }\end{array}$} & ICF1 & Eu compro produtos falsificados, com certeza \\
\hline & ICF2 & Durante um processo de compra, eu considero comprar produtos falsificados \\
\hline & ICF3 & A probabilidade de eu comprar algum produto falsificado é alta \\
\hline \multirow{6}{*}{$\begin{array}{l}\text { Racionalidade } \\
\text { Deontológica }\end{array}$} & DE01 & $\begin{array}{l}\text { É importante fazer a coisa certa, mesmo que eu ou alguém próximo a mim sofra muito com as } \\
\text { consequências }\end{array}$ \\
\hline & DE02 & Eu não preciso conhecer as consequências de uma conduta para dizer se ela é certa ou errada \\
\hline & DEO3 & $\begin{array}{l}\text { É errado decidir o que fazer pensando apenas no equilíbrio entre suas consequências positivas e } \\
\text { negativas }\end{array}$ \\
\hline & DEO4 & $\begin{array}{l}\text { Alguns atos são simplesmente errados, mesmo que possam resultar em consequências positivas para } \\
\text { muitas pessoas }\end{array}$ \\
\hline & DE05 & Há importantes regras que determinam se um ato é certo ou errado, independente das suas consequências \\
\hline & DE06 & Independente das consequências, são os valores morais que determinam é ético ou antiético \\
\hline \multirow{5}{*}{$\begin{array}{l}\text { Racionalidade } \\
\text { Teleológica }\end{array}$} & TE01 & Não é possível determinar o quanto correta ou errada é uma ação sem considerar suas consequências \\
\hline & TE02 & Uma ação é correta quando gera muitos benefícios para um grande número de pessoas \\
\hline & TE03 & $\begin{array}{l}\text { Uma ação é correta quando gera muitos benefícios para mim, minha família e aqueles com os quais eu } \\
\text { me preocupo }\end{array}$ \\
\hline & TE04 & $\begin{array}{l}\text { Quanto maior é a probabilidade de consequências positivas resultarem de uma ação, maior é a certeza } \\
\text { de que esta é a coisa certa a ser feita }\end{array}$ \\
\hline & TE05 & $\begin{array}{l}\text { Independente dos valores morais, o que determina se uma ação é correta ou errada são suas } \\
\text { consequências }\end{array}$ \\
\hline \multirow{4}{*}{ Autodeterminação } & AUD1 & $\begin{array}{l}\text { Pensar em novas ideias e ser criativo(a) é importante para mim. Eu gosto de fazer coisas de maneira } \\
\text { própria e original. }\end{array}$ \\
\hline & AUD2 & $\begin{array}{l}\text { É importante para mim tomar minhas próprias decisões sobre o que faço. Eu gosto de ser livre para } \\
\text { planejar e escolher minhas atividades. }\end{array}$ \\
\hline & AUD3 & $\begin{array}{l}\text { Eu acho que é importante demonstrar interesse pelas coisas. Eu gosto de ser curioso(a) e tentar entender } \\
\text { todos os tipos de coisas. }\end{array}$ \\
\hline & AUD4 & Para mim é importante ser independente. Eu gosto de contar comigo mesmo. \\
\hline \multirow{4}{*}{ Benevolência } & BEN1 & É muito importante para mim ajudar as pessoas ao meu redor. Eu quero cuidar do bem-estar delas. \\
\hline & BEN2 & É importante para mim ser fiel aos meus amigos. Eu quero me dedicar às pessoas próximas de mim. \\
\hline & BEN3 & Para mim, é importante entender as necessidades dos outros. Eu tento apoiar aqueles que conheço. \\
\hline & BEN4 & $\begin{array}{l}\text { Para mim é importante perdoar as pessoas que me magoaram. Eu tento ver o que há de bom nelas e } \\
\text { não ter rancor. }\end{array}$ \\
\hline
\end{tabular}


(Continuação)

\begin{tabular}{|c|c|c|}
\hline Construto & ID & Item \\
\hline \multirow{4}{*}{ Conservação } & CON1 & $\begin{array}{l}\text { Eu acredito que as pessoas deveriam fazer o que thes é ordenado. Eu acredito que as pessoas deveriam sempre seguir } \\
\text { as regras, mesmo quando ninguém está observando. }\end{array}$ \\
\hline & CON2 & $\begin{array}{l}\text { É importante para mim sempre me comportar corretamente. Eu quero evitar fazer qualquer coisa que as pessoas possam } \\
\text { achar errado. }\end{array}$ \\
\hline & CON3 & Eu acredito que sempre devo respeitar meus pais e os mais velhos. Para mim, é importante ser obediente. \\
\hline & CON4 & Para mim é importante ser sempre educado(a) com os outros. Eu tento nunca incomodar ou irritar os outros. \\
\hline \multirow{3}{*}{ Estimulação } & EST1 & Eu acho que é importante fazer várias coisas diferentes na vida. Eu sempre procuro novas coisas para experimentar. \\
\hline & EST2 & Eu gosto de me arriscar. Eu estou sempre procurando aventuras. \\
\hline & EST3 & Eu gosto de surpresas. Para mim, é importante ter uma vida emocionante. \\
\hline \multirow{3}{*}{ Hedonismo } & HED1 & Eu procuro todas as oportunidades para me divertir. É importante para mim fazer coisas que me dão prazer. \\
\hline & HED2 & Aproveitar os prazeres da vida é importante para mim. Eu gosto de me mimar. \\
\hline & HED3 & Eu realmente quero aproveitar a vida. Me divertir é muito importante para mim. \\
\hline \multirow{3}{*}{ Poder } & P0D1 & Ser rico(a) é importante para mim. Eu quero ter muito dinheiro e possuir coisas caras. \\
\hline & POD2 & $\begin{array}{l}\text { É importante para mim estar no comando e dizer aos demais o que fazer. Eu quero que as pessoas façam o que eu } \\
\text { mando. }\end{array}$ \\
\hline & POD3 & Eu sempre quero ser aquele(a) que toma as decisões. Eu gosto de liderar. \\
\hline \multirow{4}{*}{ Realização } & REA1 & É muito importante para mim demonstrar minhas habilidades. Eu quero que as pessoas admirem o que eu faço. \\
\hline & REA2 & Ser muito bem-sucedido(a) é importante para mim. Eu gosto de impressionar as demais pessoas. \\
\hline & REA3 & Eu acho que é importante ser ambicioso(a). Eu quero demonstrar o quanto sou capaz. \\
\hline & REA4 & Progredir na vida é importante para mim. Eu me empenho em fazer melhor que os outros. \\
\hline \multirow{5}{*}{ Segurança } & SEG1 & $\begin{array}{l}\text { Para mim é importante viver em um ambiente seguro. Eu evito qualquer coisa que possa colocar minha segurança em } \\
\text { perigo. }\end{array}$ \\
\hline & SEG2 & $\begin{array}{l}\text { A segurança de meu país é muito importante para mim. Eu acho que o governo deve estar atento a ameaças de origem } \\
\text { interna ou externa. }\end{array}$ \\
\hline & SEG3 & $\begin{array}{l}\text { É importante para mim que as coisas estejam organizadas e limpas. Eu realmente não gosto que as coisas estejam } \\
\text { bagunçadas. }\end{array}$ \\
\hline & SEG4 & Contar com um governo estável é importante para mim. Eu me preocupo com a preservação da ordem social. \\
\hline & SEG4 & Eu me esforço para não ficar doente. Estar saudável é muito importante para mim. \\
\hline \multirow{4}{*}{ Tradição } & TRA1 & $\begin{array}{l}\text { Eu acho que é importante não querer mais do que se tem. Eu acredito que as pessoas deveriam estar satisfeitas com o } \\
\text { que têm. }\end{array}$ \\
\hline & TRA2 & Ser religioso(a) é importante para mim. Eu me esforço para seguir minhas crenças religiosas. \\
\hline & TRA3 & Eu acho que é melhor fazer as coisas de maneira tradicional. Para mim, é importante manter os costumes que aprendi. \\
\hline & TRA4 & Para mim é importante ser humilde e modesto(a). Eu tento não chamar atenção para mim. \\
\hline \multirow{6}{*}{ Universalismo } & UN11 & $\begin{array}{l}\text { Eu acredito que é importante que todas as pessoas do mundo sejam tratadas com igualdade. Eu acredito que todos } \\
\text { deveriam ter oportunidades iguais na vida. }\end{array}$ \\
\hline & UNI2 & $\begin{array}{l}\text { É importante ouvir as pessoas que são diferentes de mim. Mesmo quando não concordo com elas, ainda quero entendê- } \\
\text { las. }\end{array}$ \\
\hline & UNI3 & $\begin{array}{l}\text { Eu acredito que todas as pessoas do mundo deveriam viver em harmonia. Promover a paz entre todos os grupos no } \\
\text { mundo é importante para mim. }\end{array}$ \\
\hline & UNI4 & $\begin{array}{l}\text { Eu quero que todos sejam tratados de maneira justa, mesmo aqueles que não conheço. Para mim, é importante proteger } \\
\text { os mais fracos. }\end{array}$ \\
\hline & UNI5 & $\begin{array}{l}\text { É importante para mim me adaptar à natureza e me encaixar nela. Eu acredito que as pessoas não deveriam modificar } \\
\text { a natureza. }\end{array}$ \\
\hline & UNI6 & Eu acredito firmemente que as pessoas deveriam preservar a natureza. Cuidar do meio ambiente é importante para mim. \\
\hline
\end{tabular}

